\section{The Interest of Coherence from Radar SAR Images in the Follow-Up of Urban Extensions of Focşani City (Romania)}

\section{K Hachemi ${ }^{1 *}$, M Visan $^{2}$, A Ozer $^{3}$, F Grecu $^{2}$, K Anouche $^{4}$, M Jurchescu ${ }^{5}$ and $M$ Nouacer ${ }^{6}$}

\begin{abstract}
Usually, the coherence image obtained by processing SAR(Synthetic Aperture Radar) images is indirectly used in the interferometry to identify and delimit different areas that disturb the phase of the radar wave. The phase plays the role of indicator and in the same time separator between areas where the elements within the pixel are unstable and the stable. Considering this principle, we use here these images with the purpose to follow the expansion of the city of Focşani, Romania (urban areas). The results show the very good coherence for the urban area, which appears in white in greyscale visualisation corresponding to maximum values of coherence. The analysis of the coherence images at different time intervals allowed us to characterise the stability of the Focşani city (without considerable extension) for almost 10 years (1995/2005). Instead, we distinguished many buildings that were multiplied towards the periphery and outside of the city. During the same period, we found out that in downtown, there were urban renovations represented by green spaces. We also found that the three pairs, which were processed by the image acquired the 01/31/2005 have a low coherence, which allows us to state that the rainfalls can be the cause of the incoherence. We also observed that the incoherence is more important within the pairs formed by ERS- 1 and ERS2 than the pairs formed by ERS-2 and ERS-2, even if the time interval between them is 24 hours (the temporal decorrelation is null or identical). This study confirms the interest of the coherence image to identify the spatial and temporal decorrelations of the pairs processed by the interferometry technique (InSAR). The role of coherence images intervenes also to distinguish the urban areas from the green or water covered areas.
\end{abstract}

\section{Keywords}

Coherence; Urban; Focşani; Radar; SAR

\section{Introduction}

Generally, the coherence of the image is indirectly used within the SAR radar interferometry as indicator of the reliability rate of the interferograms. Subsequently, it was directly used in order to identify and delimit different areas that disturb the phase of the radar wave. This delimitation is based on the fact that the coherence depends on the phase parameter of each pixel. This parameter reacts in many

*Corresponding author: K. Hachemi, LGP, UMR 8591 CNRS, Bellevue (Meudon), Laboratoire de Géographie Physique (LGP), Université Paris-Est. Université Paris 1 -Panthéon- Sorbonne, France, Tel: +33145075556; Fax: +33145075830 ; E-mail: hachemi_kamel@yahoo.fr; kamel.hachemi@u-pec.fr

Received: May 16, 2013 Accepted: December 09, 2013 Published: December 16,2013 cases as an indicator of changes within the pixel of the imaged surface, e.g. the waving of the water surface. In this case, the coherence is null and it is represented by a dark color. Instead, the stable places such as the urban ones preserve the phase and they are represented in light. However, this parameter plays the role of indicator and in the same time separator between changing areas and stable areas. However, the indirect applications of the SAR radar interferometry consist in the use of other products of interferometry such as the images of coherence. The images of coherence have been used in a remarkable way and effectively in many fields and for different purposes. They were important for many applications, such as geodynamic, agriculture, ice and soil moisture monitoring. During extraction of forest parameters by interferometry, the combinations of data of the backscattering coefficient with a DEM, it is possible to estimate the dimension of the trees in a forest $[1,2]$. Also, the biophysical characteristics of the forest areas, the combination of the coherence and the amplitude (backscattering coefficient) of JERS satellite images brought significant information on the evaluation of the biomass density and land use of the rainforest [3]. In the case of floods, the integration of the amplitude and coherence images have been used to indicate the flooded areas between the two passages of satellites allowing a precise flood mapping of the region of Béziers (southern France) [4]. The coherence images of the tandem pairs ERS-1/2 (24h) have the potential of being used for the evaluation of the volume of the trees in the boreal forests and they proved to be better than the optical data (SPOT XS) [5]. With the help of six coherence images among which three are tandem, these images (coherence) demonstrated their effectiveness in differentiating between some classes of surfaces, which were not distinguished by the radar amplitude images (backscattering). They have been used to distinguish the areas with willow-alders, fir-trees, ice, and the water in the MacKenzie delta (Canada). The willow-alder surfaces showed the highest rate of coherence followed by fir-tree, icy lakes, icy channels and water [6]. For certain categories, the coherence can be correlated with a certain type of land use in order to provide information on the changing between the two acquisitions of SAR images as in urban applications. The image of coherence can provide useful information detecting the expansion activity. The coherence in some urban areas is higher than in the ones covered by vegetation. The changing of the coherence rate, from the lowest values to the highest ones in some areas, can provide an indication of the placement of vegetation by buildings [7]. In the mapping of the boundary limits of Antarctica, the use of the coherence was profitable and has concluded that the interferometry technique using the RADARSAT images provided very satisfactory results compared to the optical images (LANDSAT and SPOT) [8]. In large-scale mapping, the images of the tandem coherence (ERS) have been also used and associated with the amplitude images (backscattered coefficient) of JERS for the monitoring and the follow-up of the boreal forest of Siberia [9]. In agriculture, the images of coherence of the tandem pairs have been used to search crop parametres (size, humidity). They showed their usefulness and their effectiveness in the monitoring during the wintertime of the wheat, sugar beet, potatoes, and corn [10]. In the mapping of the earthquake damages, the several coherence images have been used for the mapping of the damages provoked by the earthquake of Bam (26/12/2003) [11]. There is also the mapping of the forest age using the tandem pairs ERS. This mapping showed a 
space resolution that could differentiate between different forests stands and provided detailed regional age and the evaluation of the biomass in the regions of England, Scotland, and Welsh lands. This distribution and comparison of the evaluation by age associated with other information had the capacity and the potential for providing the growth rate and logging information in these areas [12]. In the study of the fire risks in the forests, the multi-pass coherence images of several bands (X, C, and $\mathrm{L}$ ) have been used for the severity evaluation of the burns in the Mediterranean forests [13]. For cartography and monitoring of dune activity in Niger, a temporal analysis of seven tandem coherence images (ERS-1/2) has highlighted the extension of active sand areas over time and dune migration [14]. Our aim in this study is to show the interest of the images of coherence in the followup of the urban extension of the Focşani city (Northern of Buzau city) and to separate and estimate the coherence rate and in the same time to assign its origin by a comparison analysis with the landscape changes between the acquired data.

\section{Coherence and Incoherence Origin}

\section{Coherence image (Coh)}

Theoretically, the coherence can be calculated by the following formula that represents the coefficient of the correlation (Coh) between the two acquired images that build the interferogram [15]. There is a mathematic formulation of the comparison between the interferogram created and the product of the both modules of the two images for each pixel, with a resampling of the new size of the pixel. Thus, the following formula allows the evaluation of the trust level of the interferogram.

$$
\operatorname{Coh}(p)=\frac{\sum_{p}^{N} S_{1}(p) \overline{S_{2}}(p)}{\sqrt{\sum_{p}^{N}\left|S_{1}(p)\right|^{2} \sum_{p}^{N}\left|S_{2}(p)\right|^{2}}}
$$

With:

$S_{1}(p)$ : Master complex radar Image for the pixel $(\mathrm{p})$;

$\bar{S}_{2}(p)$ : Joint of the Slave complex radar image for the pixel (p);

$\left|S_{1}(p)\right|$ : Module of the Master complex image for the pixel (p);

$\left|S_{2}(p)\right|$ : Module of the Slave complex image for the pixel (p);

$\mathrm{N}$ : the number of the pixels in the sampling area.

In practice, the coherence image gives an overview of the variations that may exist between the two images used, either in the registration of the images or in the geometrical conditions of acquisition likely the probable changes of the physical characteristics of the target between the two images, for all the sampling areas. $|\operatorname{Coh}(p)|$, is a correlation coefficient (the coherence degree) translated by the values between ( 0 and 1): the degree (1) shows a strong coherence between the two images against the degree (0) meaning zero coherence.

\section{Origins of the incoherence}

The reliability of an interferogram created by SAR interferometry (InSAR) is based on the coherence image: one maximum degree means a strong correlation between the phases of the both radar images processed. It is interpreted on the field by the absence of changes of surface properties between the two acquisition dates, and the same level of distribution of the speckle [16]. In the opposite case, the degree of minimum coherence is translated on the field by the fact that the elements in the two pixels corresponding to the both images had undergone changes or the two pixels simply do not have the same position. The low coherence between the two acquisitions can have many origins: a large difference of the angle of incidence between the two acquisitions especially for the slopes oriented towards the radar look; the change of the physical characteristics of the surface; the surfaces in constant motion as the lakes, seas, etc.; the areas covered by vegetation due to the rapid movements such as wind effect; all the mouvements on the land can affect the phase between the two acquisitions (passing vehicles, plowing, etc.). Then, the incoherence can be divided in three distinct sources: the incoherence due to the change in the scene (elements in the pixel); the incoherence due to the different positions of the orbits and the incoherence due to the signal noise $[17,18]$. Here, the athmospherical effects are supposed to be negligeable. Thus, the coherence results can be written as:

$$
\text { Coh }=f\left(\text { Coh }_{\text {scene }} . \text { Coh }_{\text {spat }} . \text { Coh }_{\text {noise }}\right)(2)
$$

The separation of the coherence sources is difficult due to the relation between the parameters considered as a close multiplicative relation. In other terms, the coherence is an estimate of the degree of stability of the phase between the both radar images acquired in almost identical geometric conditions of the same area. This stability and instability of the phase are represented in a grey scale by coherence corresponding to dark areas and incoherence corresponding to bright areas respctively.

\section{The Study Area and the Data Used}

\section{Location and the study area characteristics}

The study area is located in the outside of the Eastern Carpathians, more precisely in the Subcarpathian Curvature in the S.E of Romania (Figure 1). This area is frequently affected by phenomena such as mudflows, floods, earthquakes and landslides. The Buzau Valley is known for the presence of mud volcanoes resulting from the rise of gas from oil layers at 200-300 m depth. This area is delimited by the following geographical coordinates: latitude from South to North: $44.813^{\circ} / 45.926^{\circ}$; longitude from West to East: $26.089^{\circ} / 27.614^{\circ}$. The study area is characterized by:

(1) A flat area corresponding to the plains of Buzau to the East; the mean altitudes being between $30 \mathrm{~m}$ to $80 \mathrm{~m}$;

(2) A high area to the west corresponding to the Subcarpathians

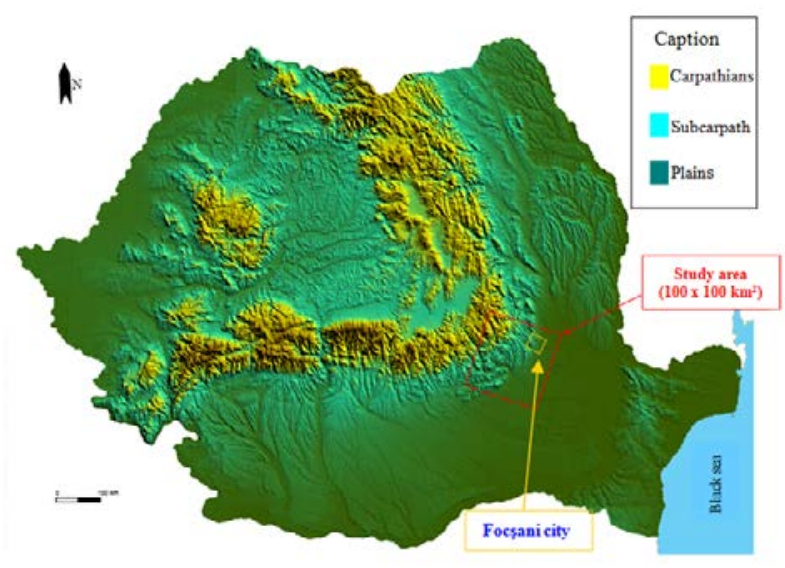

Figure 1: Map of Romania. The study area is indicated. 
Citation: Hachemi K, Visan M, Ozer A, Grecu F, Anouche K, et al. (2013) The Interest of Coherence from Radar SAR Images in the Follow-Up of Urban Extensions of Focşani City (Romania). Geoinfor Geostat: An Overview 1:4.

and Carapathians which can be divided in two subareas:

(i) An intermediate area with the altitudes ranging from $300 \mathrm{~m}$ to $400 \mathrm{~m}$ and

(ii) A higher area with altitudes above $1000 \mathrm{~m}$.

These variations of relief can have different responses to the radar signal backscattered to the sensor:

(1) A flat land corresponding to the plains of Buzau to the East;

(2) An intermediate area: slopes oriented to the radar look;

(3) One very hilly area between the Subcarpathians and Carpathians to the West.

\section{Focşani city}

The Focşani city is situated in the northern part of the study area and at $174 \mathrm{~km}$ to the North -East from the capital of Bucharest, in Moldavia, the historical province of Romania. Its geographical coordinates are: $45^{\circ} 42^{\prime} 00^{\prime \prime}$ North, $27^{\circ} 10^{\prime} 59^{\prime \prime}$ East, with an altitude of $49 \mathrm{~m}$ and a surface of $48.15 \mathrm{~km}^{2}$. The population is estimated to 103219 inhabitants (99 907 inhab. in 2007) and a density of 2075 inhab. $/ \mathrm{km}^{2}$. This municipality of the East of Romania is the seat of the Vrancea County, on the shores of the Milcov River, in the historical region of the Moldavia. It is situated on the border between Moldavia and Wallachia, which allowed once the development of an important commerce center between the Russian Empire and Balkans. It is considered as the first capital of the united principalities of Moldavia and Wallachia and it is also nicknamed "the city of the Milcov river". The older and larger part of the city is situated in Moldavia. On the $24^{\text {th }}$ January 1859, the city (Focşani) played an important role in favour of the union of the Wallachia and Moldavia and during the formation of the Modern Romanian State (the National United State of Romania), after the Great Union in 1918 (this event is immortalized by the obelisque in the Union Place).

\section{Data used}

The data used are SLC (Single Look Complex) radar images from ERS-1/ERS-2 and ENVISAT satellites. These images have been processed by the impulsion compression in radial direction in distance and by the synthesis of the SAR opened in azimuthal direction beginning with the same processing and archiving center (UK-PAF). The acquisition of the images is descendant (day acquisition) with polarisation V/V and "C" flight strip of wavelength of $5.56 \mathrm{~cm}$. For this study, we used 8 radar images SAR SLC:

(i) Four from ERS satellites: one from ERS-1 and three from ERS-2, with 1 tandem pair (ERS-1/ERS-2). The acquisition dates are 28 and 29 May 1995, 17 June 1996 and 29 November 1999, respectively;

(ii) 4 images from ENVISAT satellite for which the acquisition dates are 18 Octobre 2004, 27 December 2004, 31 January 2005 and 11 April 2005. These images cover a surface of $100 \mathrm{~km} \mathrm{x} 100 \mathrm{~km}$ with a resolution of $4 \mathrm{~m}$ in azimuth and $20 \mathrm{~m}$ in distance. All the images used have the same track 193 and frame 2691.

\section{Methodology and Results}

In this work, we have generated 12 coherence images with a resolution of $20 \mathrm{~m}$ from the 8 SLC images by using the radar interferometry technique (InSAR) with softwares DORIS/ DIAPASON. We calculated the coherence in a separate way for ERS and ENVISAT satellites because of the impossibility to combine ERS and ENVISAT images. First, we processed the 4 images of the satellites ERS-1 and ERS-2 in an independent way after the 4 images of the ENVISAT satellite. The results are shown with six (6) coherence images generated with the pairs ERS and six (6) other coherence images generated with pairs ENVISAT in Figures 2 and 3.

Then, we calculated the coherence rate of each pair processed by InSAR. We have divided the coherence image in two parts according to the characteristics of the study area: one part corresponding to the plains, which are flat, and one part corresponding to the higher and hilly relief. We calculated the average coherences of the whole scene (CS) and for the other two parts separately (Plain (CPla) and Relief (CRel)). The results are presented in Tables 1 and 2.

We now focused on the Focşani city. We calculated and compared

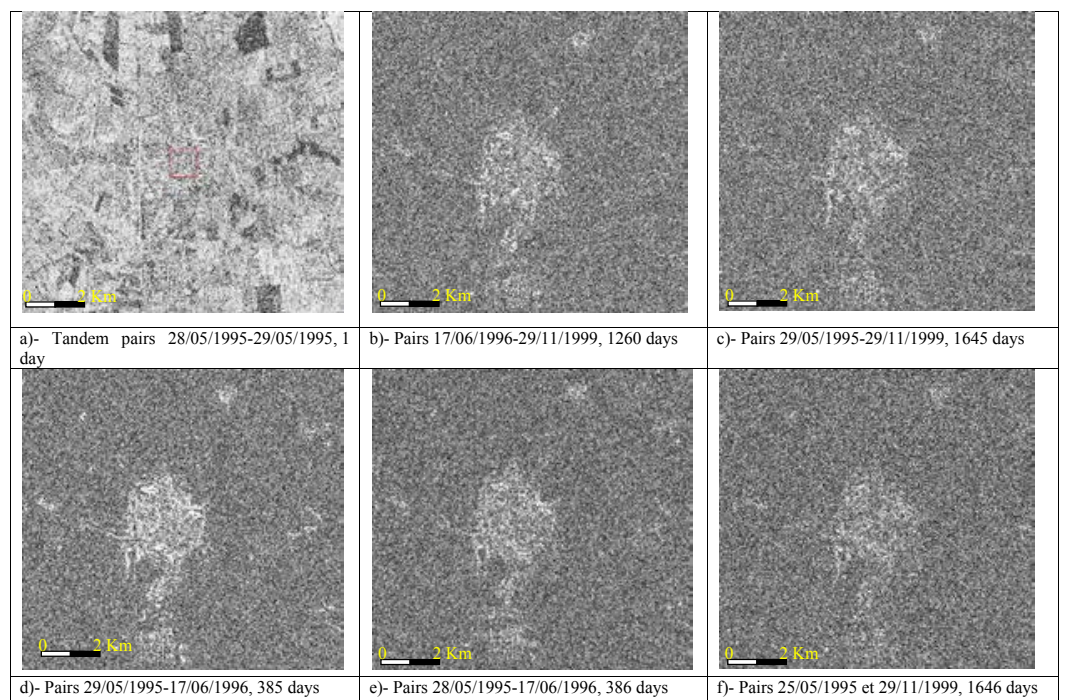

Figure 2: The coherence images with $20 \mathrm{~m}$ of resolution of all processed pairs over the Focşani city (ERS Pairs). Red rectangle in a) indicates or locates the center of Focşani city. 
Citation: Hachemi K, Visan M, Ozer A, Grecu F, Anouche K, et al. (2013) The Interest of Coherence from Radar SAR Images in the Follow-Up of Urban Extensions of Focşani City (Romania). Geoinfor Geostat: An Overview 1:4.

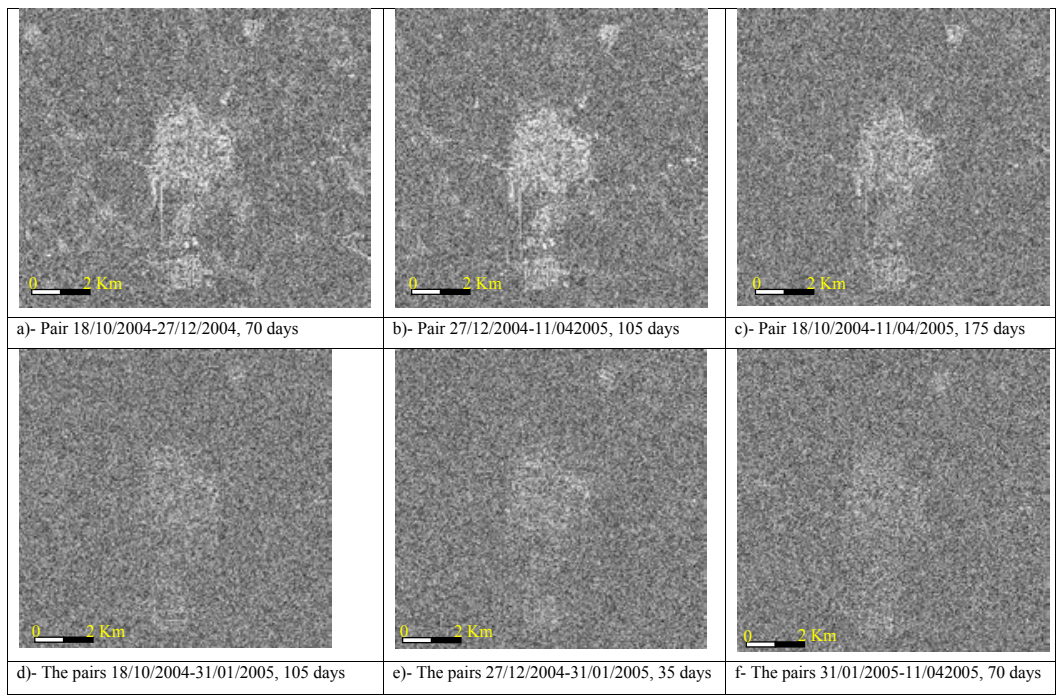

Figure 3: The coherence images of $20 \mathrm{~m}$ resolution of all processed pairs of Focşani city (ENVISAT Pairs).

Table 1: The coherence level of each ERS pair.

\begin{tabular}{|c|c|c|c|c|c|c|c|c|}
\hline Data Master/Slave & $B_{\text {temp }}$ [days] & $B$ [m] & $B_{\text {perp }}[\mathrm{m}]$ & $C_{s}[0-1]$ & $C_{\text {Rel }}[0-1]$ & $\mathrm{C}_{\mathrm{Pla}}[0-1]$ & Orbit $_{\text {conv }}$ [deg] & Hamb [m] \\
\hline 28-05-1995/29-05-1995 & 1 & 90.5 & -79 & 0.616227 & 0.553663 & 0.705942 & 0.000818386 & 120.4 \\
\hline $28-05-1995 / 17-06-1996$ & 386 & 157.9 & -150.7 & 0.418489 & 0.418655 & 0.418293 & 0.0069804 & 63.2 \\
\hline $28-05-1995 / 29-11-1999$ & 1646 & 177 & -129 & 0.415918 & 0.417835 & 0.414086 & 0.0112849 & 73.8 \\
\hline 29-05-1995/17-06-1996 & 385 & 75.3 & -75.2 & 0.470863 & 0.471405 & 0.470394 & 0.00616376 & 126.7 \\
\hline 29-05-1995/29-11-1999 & 1645 & 99.2 & -62.3 & 0.467496 & 0.468213 & 0.466779 & 0.0104752 & 152.7 \\
\hline 17-06-1996/29-11-1999 & 1260 & 80.7 & 31.2 & 0.467884 & 0.468651 & 0.467179 & 0.00436376 & -305.5 \\
\hline
\end{tabular}

$B_{\text {temm }}:$ Temporal Baseline

$B:$ Baseline (distance between the two radars)

$\mathrm{B}_{\text {perr }}:$ Perpendicular Baseline

Orbit $_{\text {conv: }}$ : Angle between the orbits

$\mathrm{H}_{\text {amb }}$ : Altitude of ambiguity [height $=\mathrm{h} \_$amb ${ }^{*}$ phase $\left./ 2 \pi\right]$

$C_{s}[0-1]$ : The level of the average Coherence for entire scene.

$C_{\text {Rel }}[0-1]$ : The level of the average Coherence for the part of relief of the scene imaged.

$\mathrm{C}_{\text {Plai }}^{\mathrm{Rel}}[0-1]$ : The level of the average Coherence for the part of plain of the scene imaged.

Table 2: The coherence level of each ENVISAT pair.

\begin{tabular}{|c|c|c|c|c|c|c|c|c|}
\hline Data Master/Slave & $\mathbf{B}_{\text {temp }}$ [days] & B [m] & $B_{\text {perp }}[\mathrm{m}]$ & $C_{s}[0-1]$ & $C_{\text {Rel }}[0-1]$ & $\mathrm{C}_{\mathrm{Pla}}[0-1]$ & Orbit $_{\text {conv }}$ [deg] & Hamb [m] \\
\hline $18-10-2004 / 27-12-2004$ & 70 & 330.7 & -304.2 & 0.485681 & 0.481130 & 0.489756 & 0.0137288 & 30.4 \\
\hline $18-10-2004 / 31-01-2005$ & 105 & 664.1 & -619.3 & 0.469287 & 0.468578 & 0.470187 & 0.00616097 & 15 \\
\hline $18-10-2004 / 11-04-2005$ & 175 & 522.2 & -499.7 & 0.471925 & 0.470850 & 0.473134 & 0.00361708 & 18.5 \\
\hline $27-12-2004 / 31-01-2005$ & 35 & 344.4 & -326.3 & 0.472717 & 0.472599 & 0.472660 & 0.00756989 & 28.4 \\
\hline $27-12-2004 / 11-04-2005$ & 105 & 215.8 & -214.5 & 0.484459 & 0.477235 & 0.492050 & 0.0101461 & 43.1 \\
\hline $31-01-2005 / 11-04-2005$ & 70 & 149.2 & 120.6 & 0.472499 & 0.472699 & 0.472136 & 0.00262443 & -76.7 \\
\hline
\end{tabular}

B : Temporal Baseline

$B$ : Baseline (distance between the two radars)

$\mathrm{B}_{\text {perp }}$ : Perpendicular Baseline

Orbit ${ }_{\text {conv }}$ : Angle between the orbits

$\mathrm{H}_{\mathrm{a}}$ : Altitude of ambiguity [height $=\mathrm{h} \_$amb*phase $\left./ 2 \pi\right]$

$C_{S}[0-1]:$ The level of the average Coherence for entire scene.

$C_{R e l}[0-1]$ : The level of the average Coherence for the part of relief of the scene imaged.

$\mathrm{C}_{\text {Plai }}[0-1]$ : The level of the average Coherence for the part of plain of the scene imaged.

the dimensions of the city during different periods with the coherence images and we interpreted the obtained results. Figures 2 and 3 represent the coherences on the Focşani city (resolution $20 \mathrm{~m}$ ).

We followed the same procedure for the ENVISAT pairs, for which the time intervals are smaller, and the baselines larger than the ERS ones. We calculated the average coherences in the same way and plotted graphs in order to see the possible relationship between different parameters of the images.

\section{Interpretation and Discussions}

Coherence levels of the scene and of the two parts (relief and plain) being determined, we made graphs in order to search possible relationships that may exist between the geometrical parameters and the coherence as well as the time interval of the data acquisitions. 
Citation: Hachemi K, Visan M, Ozer A, Grecu F, Anouche K, et al. (2013) The Interest of Coherence from Radar SAR Images in the Follow-Up of Urban Extensions of Foçsani City (Romania). Geoinfor Geostat: An Overview 1:4.

The Graph 1 shows well that the coherence level of the ERS pairs covering a time period greater than 1260 days is higher than the pair covering 386 days, although the elapsed time is three times larger The same can be noted for other pairs (1645 days). This indicates that there is no direct relation between the time interval elapsed and the coherence, even though the shorter the interval, the less the incoherence is due to the landscape as the tandem pair shows. Graph 2 also shows that there is no apparent relationship between the perpendicular Baseline and the coherence level.

As the same, Graph 3 does not show relationships between coherence level and the geometrical parameters of the images acquisition, i.e. the orbit angles.

This analysis shows and confirms that there is no direct relation between the coherence level and (the temporal and spatial Baseline). But the relation is the function of all these parameters as well as others such as the noise. So we can say that there is a multiplicative relation and not an adaptive one. Therefore, it is difficult to separate the origins of the recorded incoherences.

\section{Comparing the coherence and the acquisition dates of SAR images}

In Graphs 4 and 5, the comparison of the coherence with the acquisition dates (Master: first date/Slave: second date), shows that from October and December, there is a better coherence in confront of the other dates. This coherence is better in the plains (the flat part of the scene) than in the reliefs (the high part of the scene). On the other hand, from December to January, there is a decreasing trend of the coherence. This decline may be explained by the different sources such as the climate changes (precipitations) occurred during the months of December and January, but absent during the months
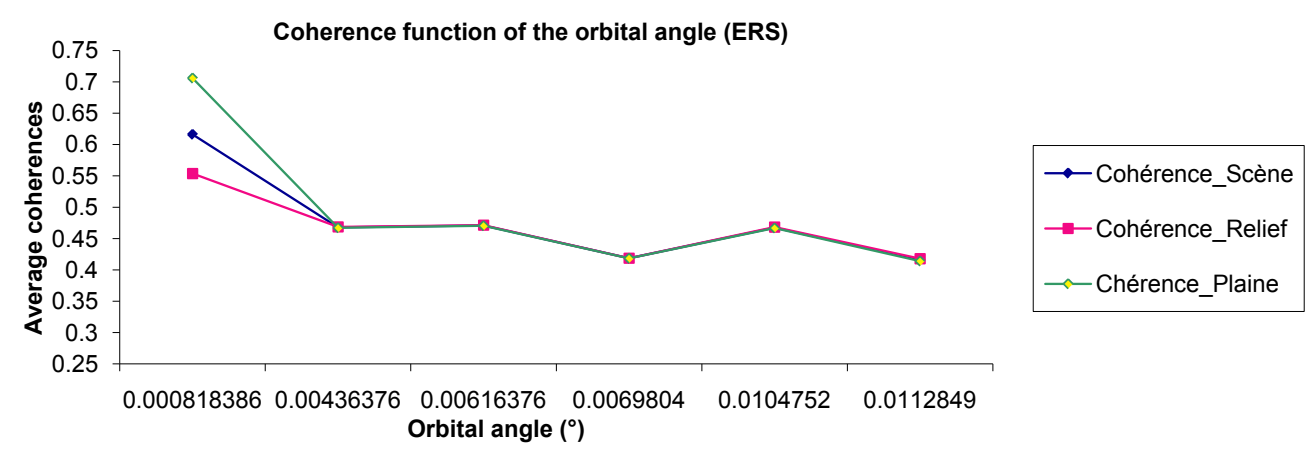

Graph 1: Coherence function of time interval (ERS).

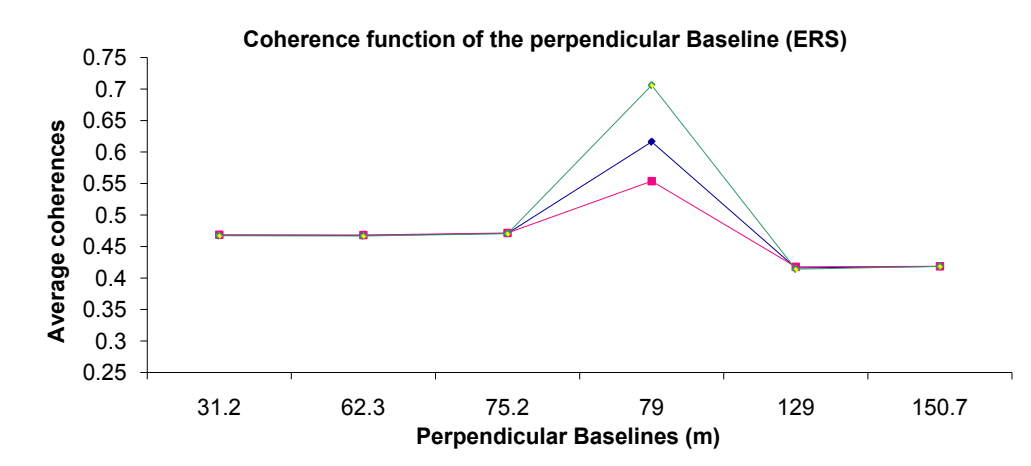

Graph 2: Coherence function of the perpendicular Baseline (ERS).
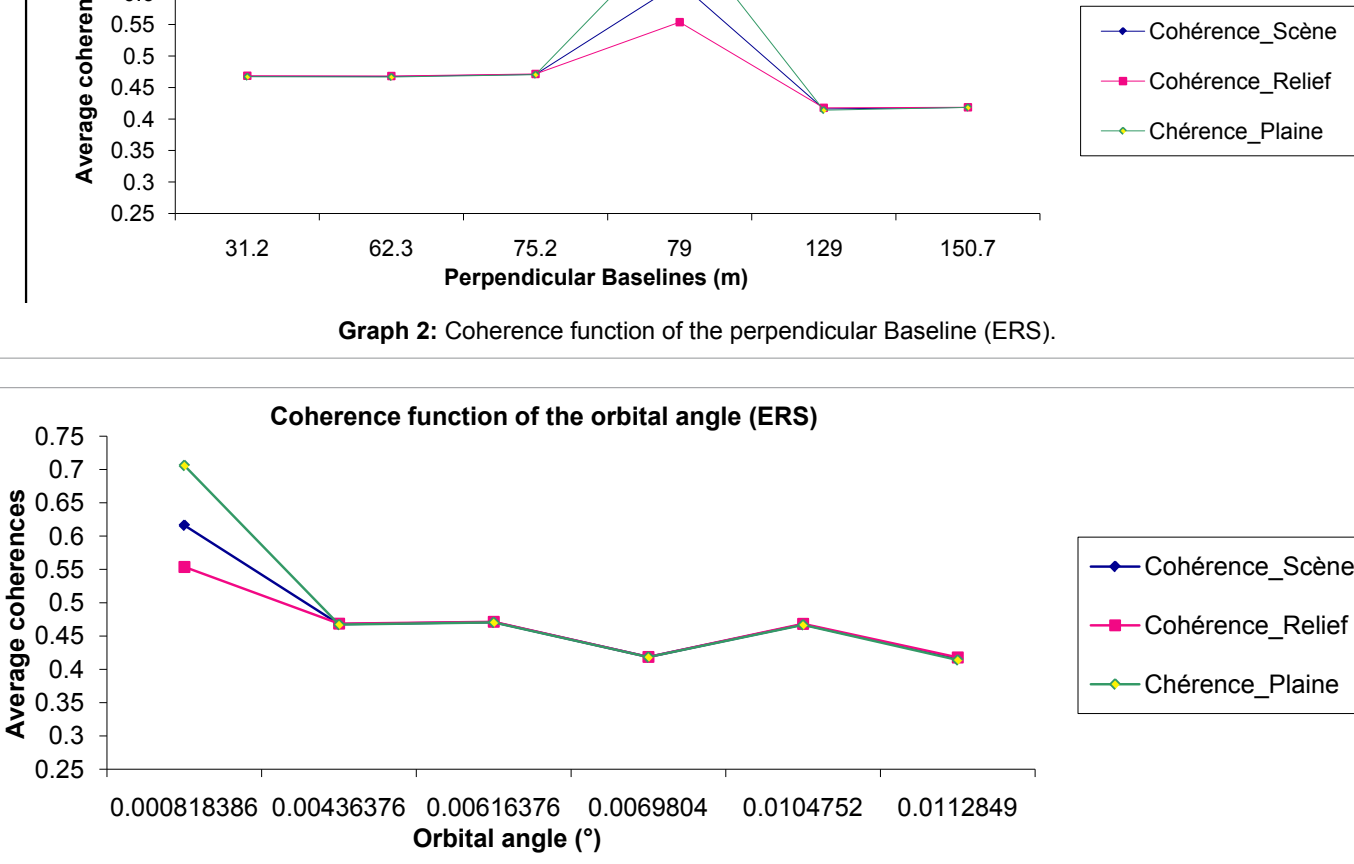

Graph 3: Coherence function of the orbital angle (ERS). 
Citation: Hachemi K, Visan M, Ozer A, Grecu F, Anouche K, et al. (2013) The Interest of Coherence from Radar SAR Images in the Follow-Up of Urban Extensions of Foç̧ani City (Romania). Geoinfor Geostat: An Overview 1:4.

of October and November. During the following months (from February to April), the average coherence is almost the same, which explains that the sources of this incoherence are the same during these months. Moreover, by analysis the average coherence of the pairs during the months of December and April, we found that there is an increase of the coherence, which is seemingly contradictory with the other pairs. The addition of the poor coherence of the interval of 35 days (12/27/2004 and 01/31/2004) with the one of 70 days $(01 / 31 / 2004$ and $04 / 11 / 2005)$, gives a poor coherence for the interval of 105 days of the following months. Although, in this case, we notice that for the interval of 105 days (12/27/2004 and 04/11/2005), there is an increase of the average coherence. This is probably explained by a space correlation that is due to the geometrical conditions of the images as the Baseline. For this pair, the perpendicular Baseline is , which gives a better relative coherence in all scenes as also for the plain and for the relief (Graphs 5 and 6).

Comparison of the coherence with acquisition dates for Season 1 and Season 2: The first season is from October to January: 70 days (10-18-2004/12-27-2004) and 105 days (10-18-2004/01-31-2005) (Graph 6). The second season is from December to April 70 days (0131-2005/04-11-2005) and 105 days (12-27-2004/04-11-2005) (Graph 7).

Comparison of the coherence depending on the seasons: We notice that in Graph 8 the two seasons are in total contradiction for
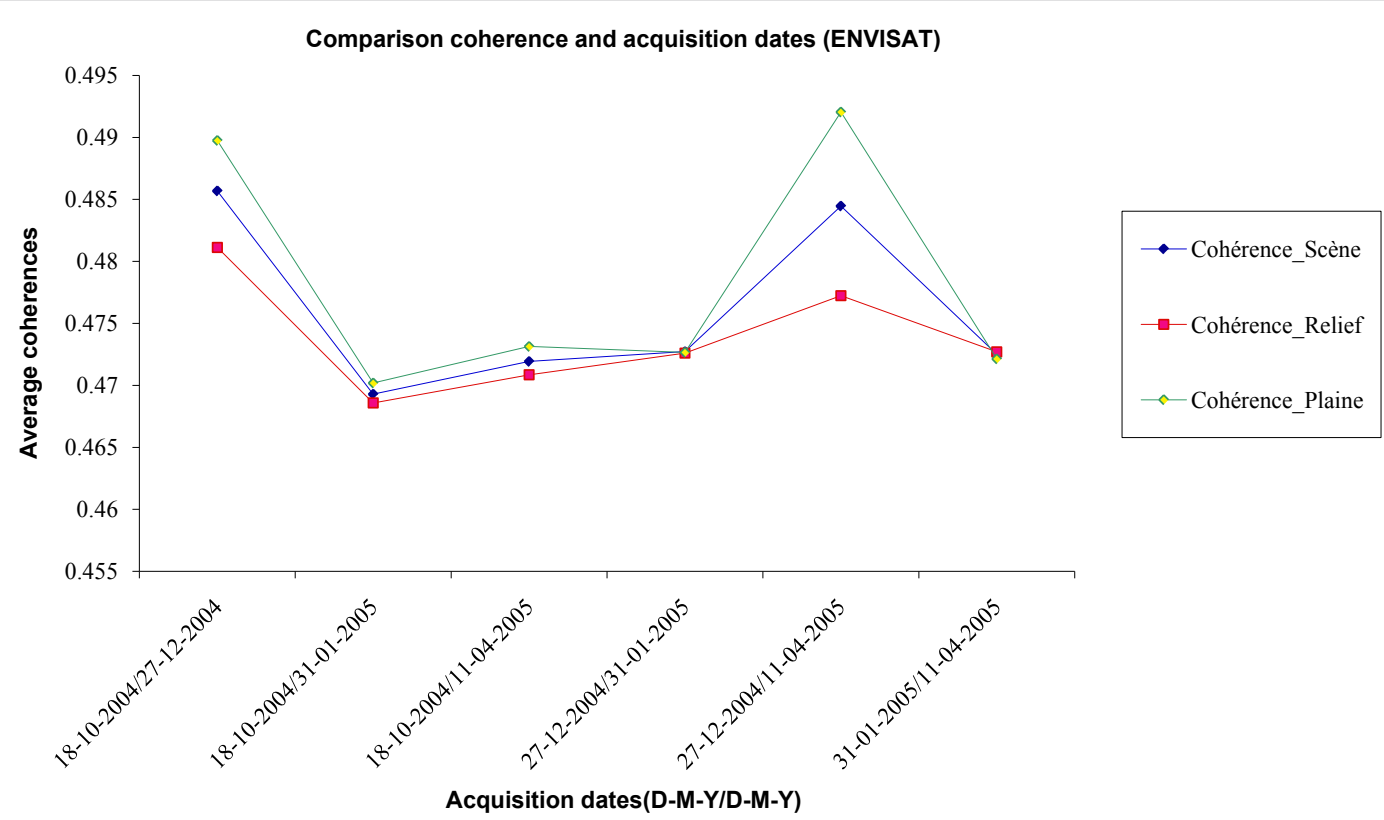

Graph 4: Average coherences depending on the acquisition data.

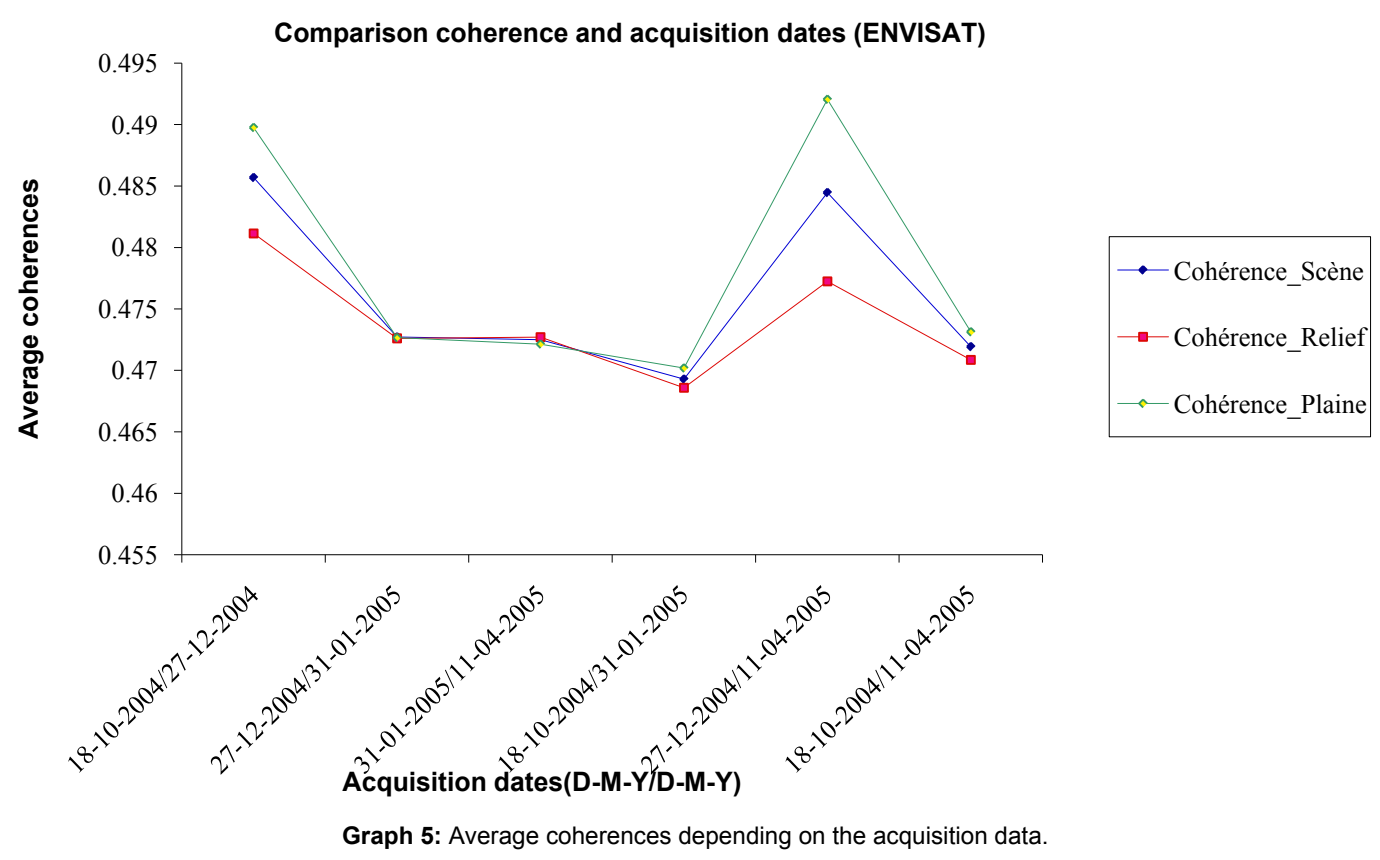


Citation: Hachemi K, Visan M, Ozer A, Grecu F, Anouche K, et al. (2013) The Interest of Coherence from Radar SAR Images in the Follow-Up of Urban Extensions of Focşani City (Romania). Geoinfor Geostat: An Overview 1:4.

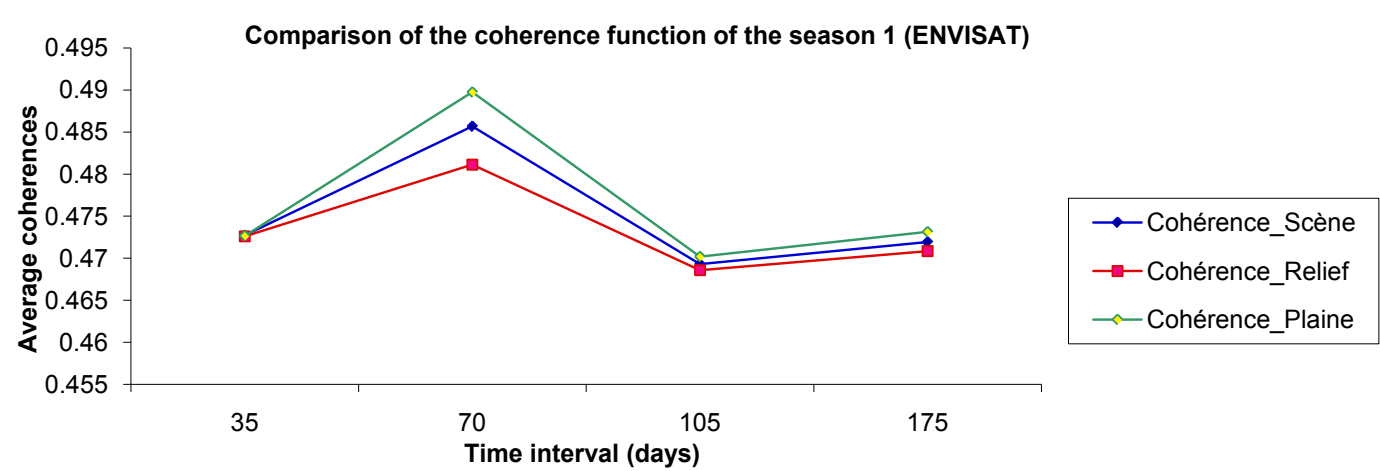

Graph 6: Comparison of the coherence function of the season 1 (ENVISAT)

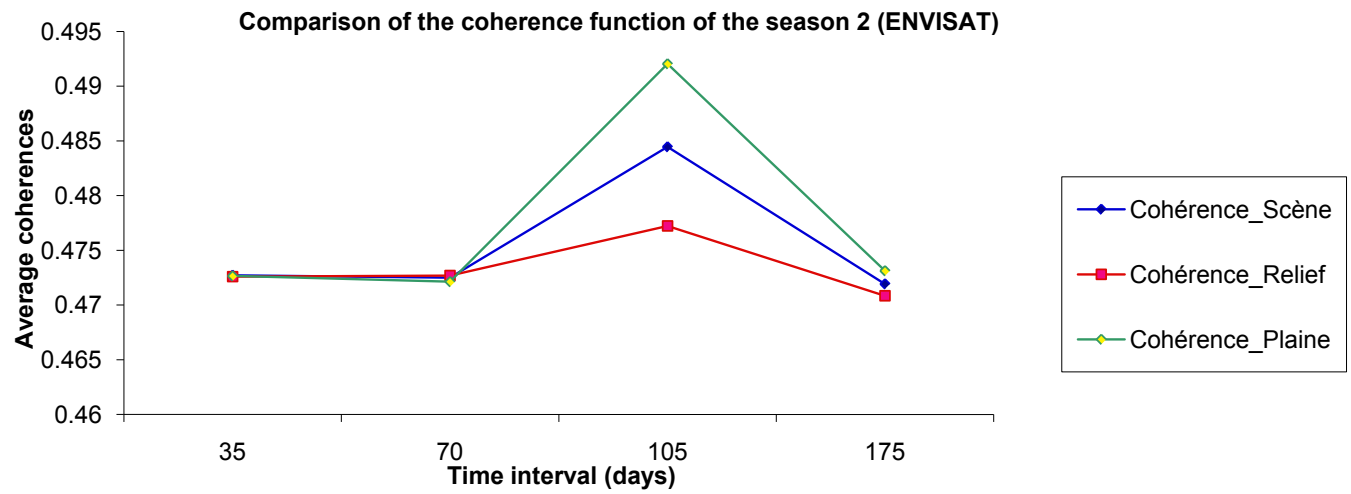

Graph 7: Comparison of the coherence function of the season 2 (ENVISAT)

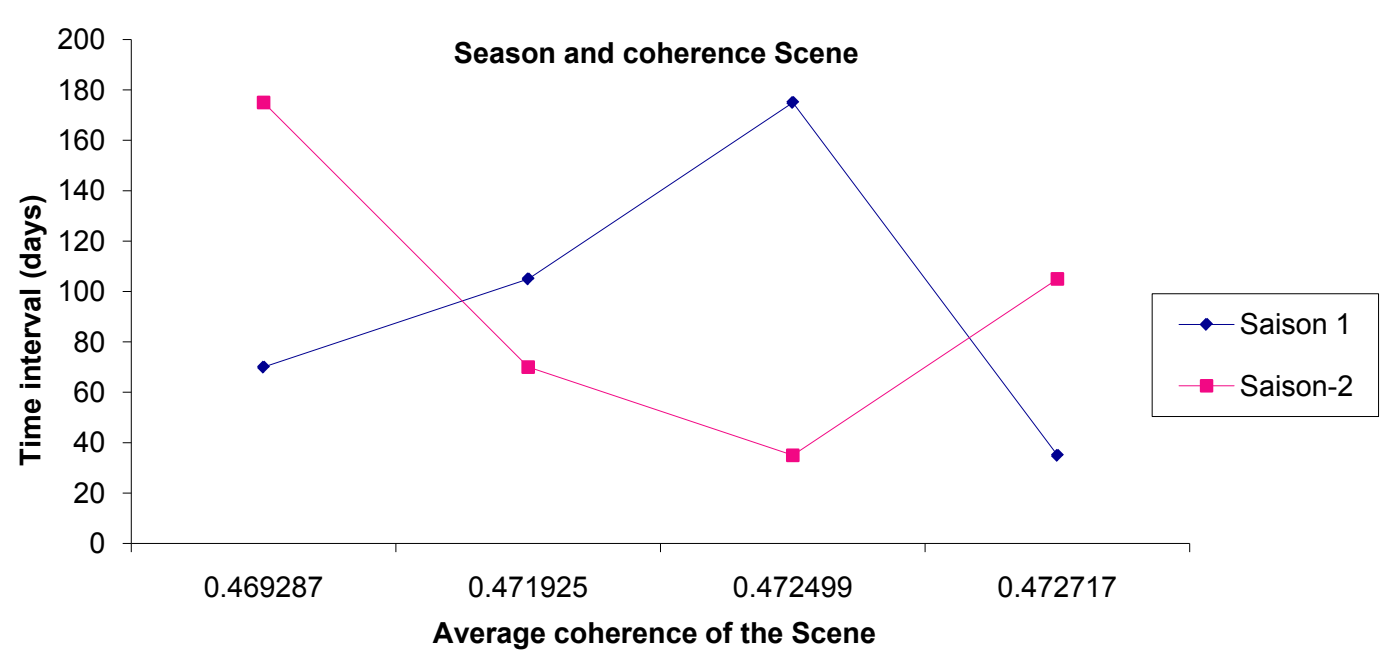

Graph 8: Season and coherence Scene.

the coherence; where the first season provides a good coherence, the second one provides a poor coherence and vice versa, which is due to the temporal decorrelation. In Graphs 9 and 10 we suggest that the space coherence is influenced by the land geomorphology.

Comparison of coherence with the time interval in days, the perpendicular Baseline $\left(B_{\perp}\right)$, the orbit angle and the ambiguity altitude $\left(\mathbf{H}_{\mathrm{amb}}\right)$ : The analysis of the pairs (Graphs 11-14) confirms that there is no direct relationship between the coherence and one of the geometrical parameters of image acquisitions implying a functional relation. We observe that the pairs formed with the dates from the 31th of January 2005 present low coherence ( Figures 3-d, e, and $f$ ) even if the spatial Baselines are different. This implies that the coherence in these three pairs is worsened without doubt because of the rainfalls measured at $7 \mathrm{~mm} / \mathrm{m}^{2}$ occurred during the acquisition of 
Citation: Hachemi K, Visan M, Ozer A, Grecu F, Anouche K, et al. (2013) The Interest of Coherence from Radar SAR Images in the Follow-Up of Urban Extensions of Focşani City (Romania). Geoinfor Geostat: An Overview 1:4.
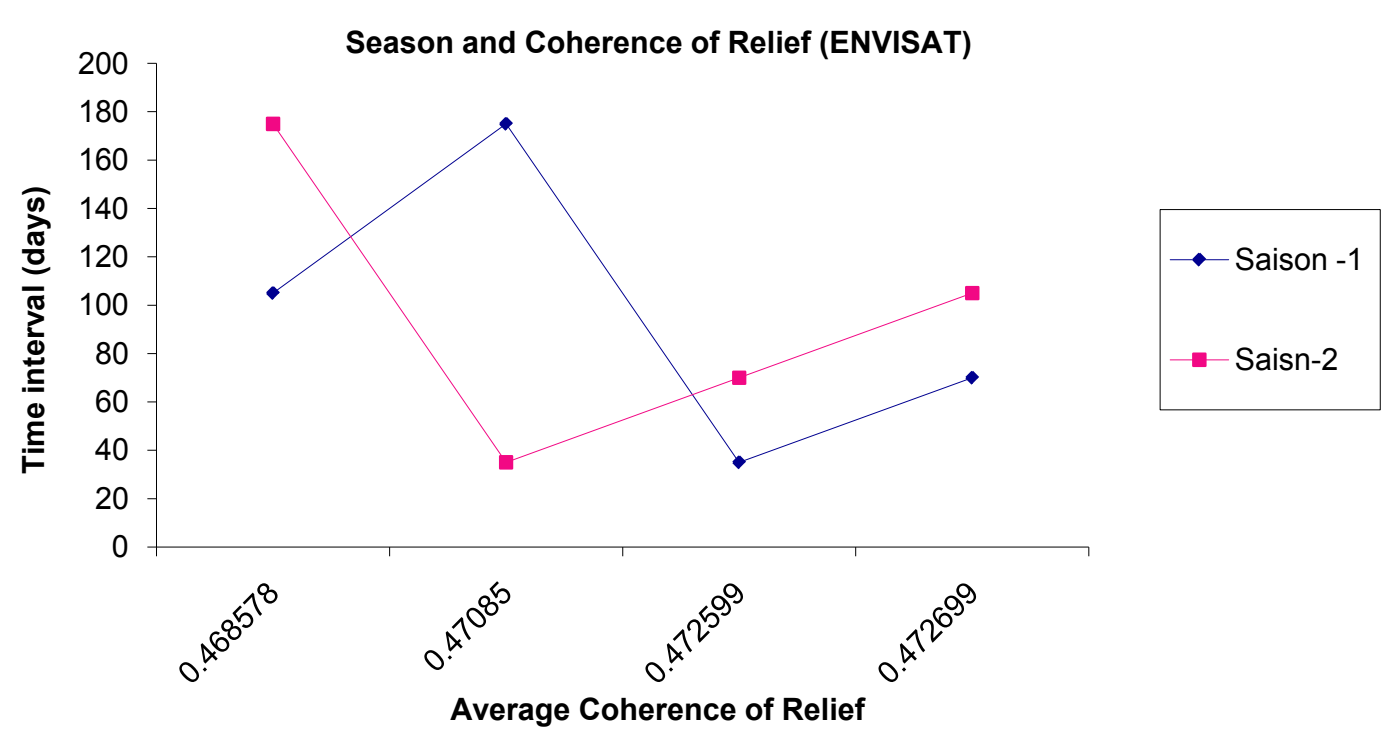

Graph 9: Season and Coherence of Relief (ENVISAT).
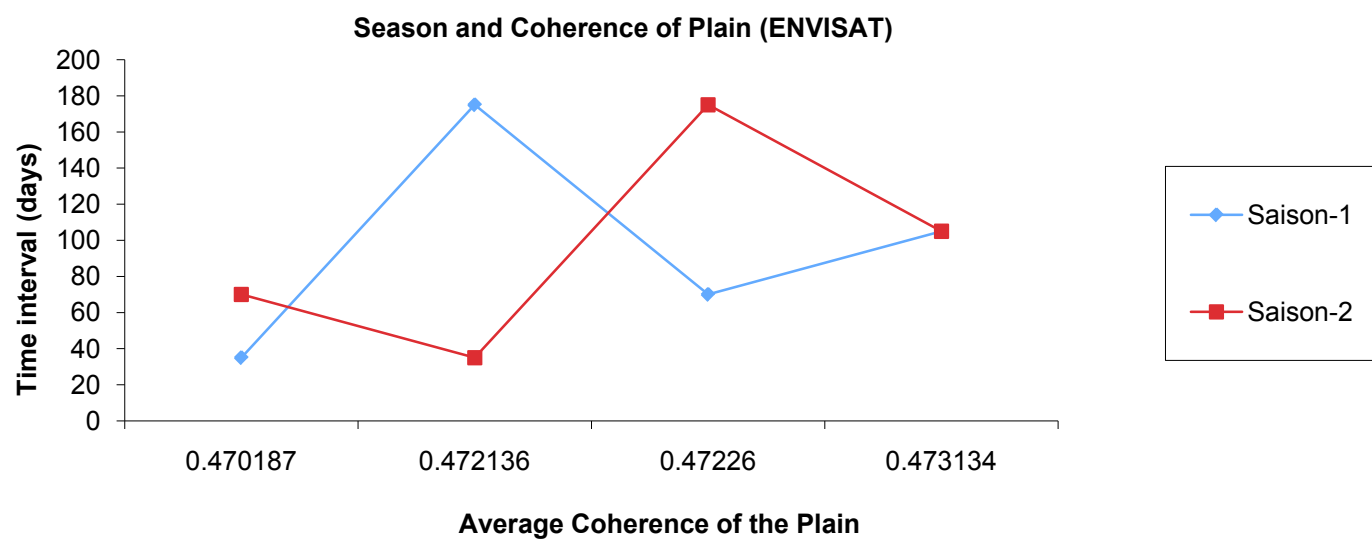

Graph 10: Season and Coherence of Plain (ENVISAT).

Comparison coherence (ENVISAT)

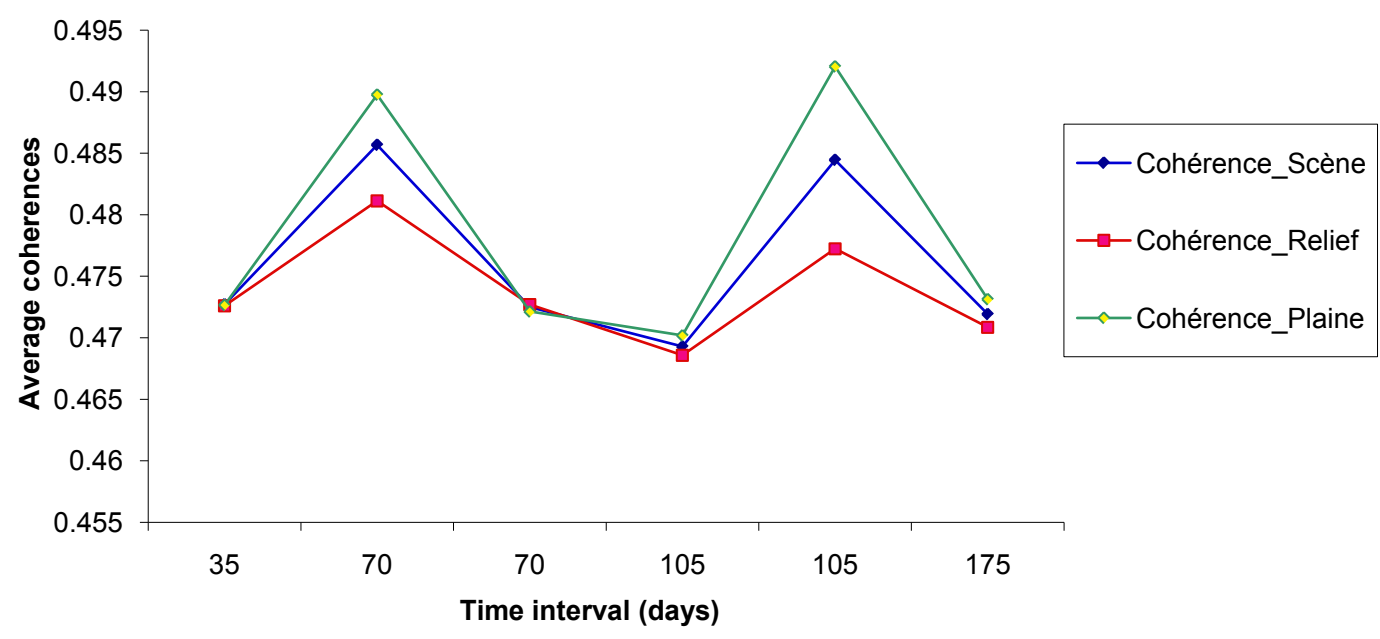

Graph 11: Comparison coherence (ENVISAT). 
Citation: Hachemi K, Visan M, Ozer A, Grecu F, Anouche K, et al. (2013) The Interest of Coherence from Radar SAR Images in the Follow-Up of Urban Extensions of Focşani City (Romania). Geoinfor Geostat: An Overview 1:4.

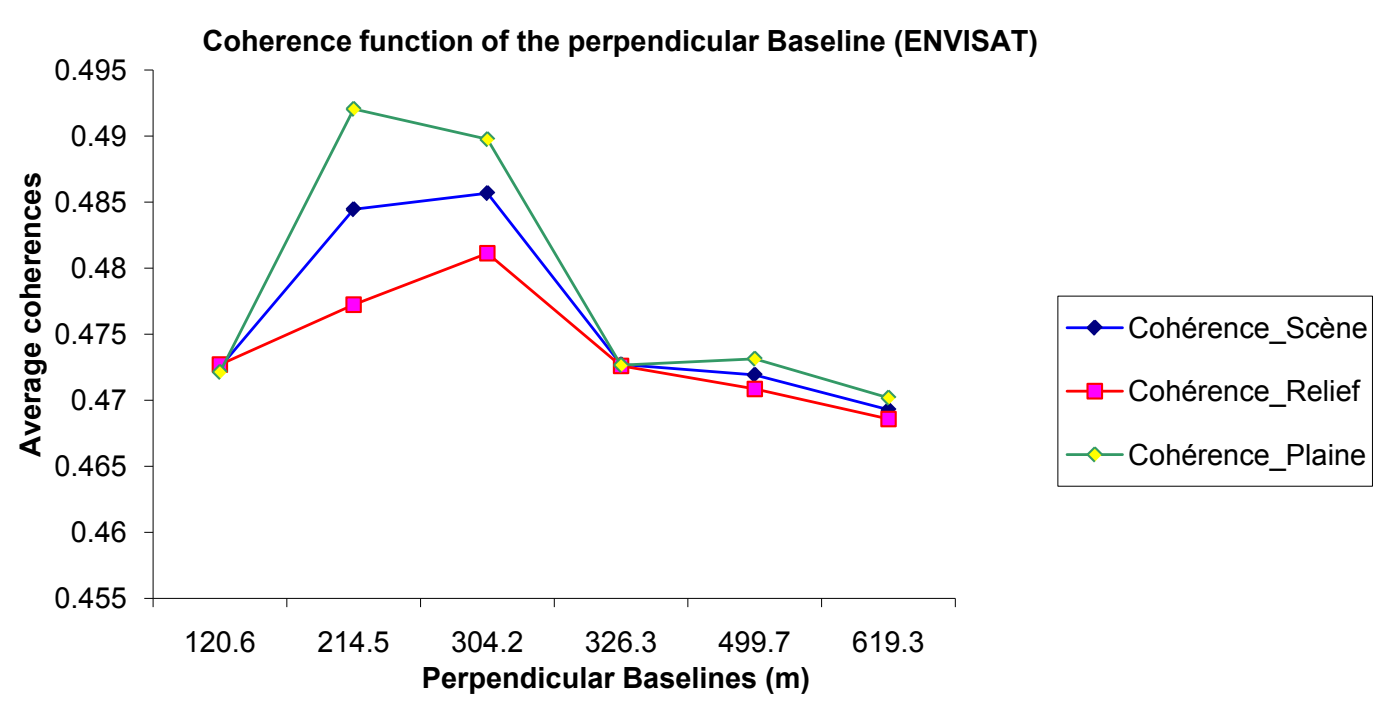

Graph 12: Coherence function of the perpendicular Baseline (ENVISAT).

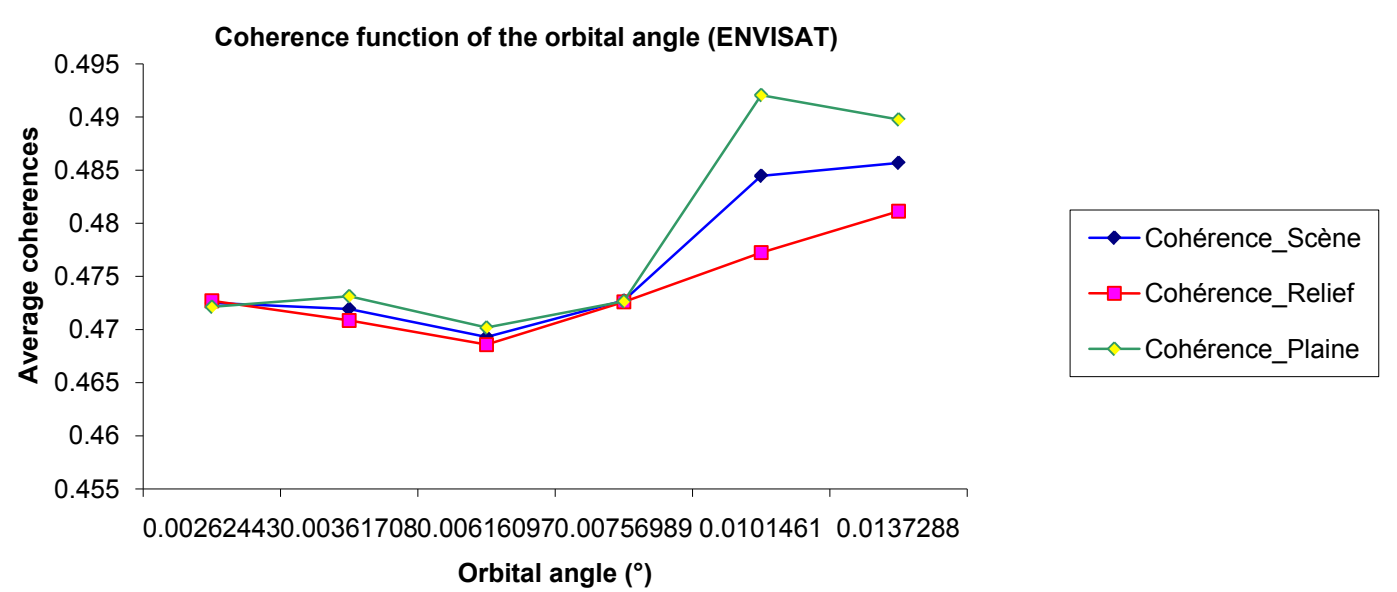

Graph 13: Coherence function of the orbital angle (ENVISAT).

Coherence function of the altitude of ambiguity (Hamb) (ENVISAT)

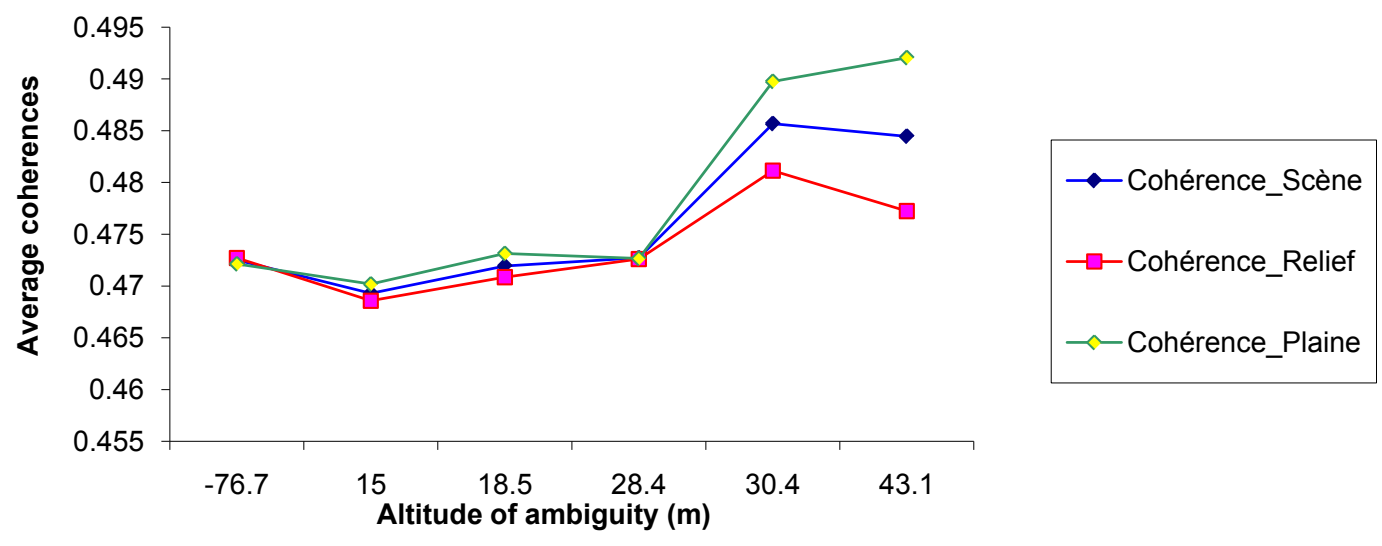

Graph 14: Coherence function of the altitude of ambiguity (Hamb) (ENVISAT). 
Citation: Hachemi K, Visan M, Ozer A, Grecu F, Anouche K, et al. (2013) The Interest of Coherence from Radar SAR Images in the Follow-Up of Urban Extensions of Focşani City (Romania). Geoinfor Geostat: An Overview 1:4.

\section{1/31/2005 image.}

\section{Estimation of the spatial coherence level}

The coherence images produced may give us an idea of the coherence level due to the spatial decorrelation and at the same time, its relation with the Baseline. In this case, we suppose that the relationship between the coherence and their sources is adaptative in order to estimate the spatial decorrelation level.

We write the coherence of two pairs, for which the time period of observation differs from 1 day, as:

$$
\begin{aligned}
& \mathrm{Coh}_{20221 \_6059}=\mathrm{Coh}_{\text {temp }}+\mathrm{Coh}_{\text {spat }} \\
& \mathrm{Coh}_{548 \_6059}=\mathrm{Coh}_{\text {temp }}+\mathrm{Coh}_{\text {spat }}
\end{aligned}
$$

Considering that the time intervals of the both pairs are at 386 days and 385 days, respectively, we assume that these two temporal coherences are equal, implying, i.e.:

$$
\operatorname{Coh}_{\text {temp (20221_6059) }}=\text { Coh }_{\text {temp }\left(548 \_6059\right)}
$$

Then, the difference between these two coherences allows estimating the spatial coherence, which can be written as following:

$$
\mathrm{Coh}_{20221_{1} 6059}-\mathrm{Coh}_{548 \_6059}=\mathrm{Coh}_{\text {spat }}=0,052374
$$

Similarly for the other two pairs which are in the same temporal configuration with time intervals at 1646 days and 1645 days, respectively. Then, the coherence difference can be also written as:

$$
\mathrm{Coh}_{20221 \_24095}-\mathrm{Coh}_{548 \_24095}=\mathrm{Coh}_{\text {spat }}=0,051578
$$

Temporal coherence for the 386 days-period and for the 1645 days-period being assumed to be equal to the ones of the 385 daysperiod and of the 1646 days-period, respectively, the difference of the total coherence allows estimating the spatial coherence. This coherence can be compared with the Baseline, which represents the first different geometrical parameter between the both images. If we calculate and compare the Baselines of these four pairs we will obtain:

$$
\begin{aligned}
& B_{\perp\left(20221 \_6059\right)}=150,7 m \text { and } B_{\perp\left(548 \_6059\right)}=75,2 m \\
& B_{\perp\left(20221 \_6059\right)}-B_{\perp\left(548 \_6059\right)}=75,5 m \\
& B_{\perp\left(20221 \_24095\right)}=129 m \text { and } B_{\left(548 \_24095\right)} \\
& B_{\perp\left(20221 \_24095\right)}-B_{\perp\left(548 \_24095\right)}=66,7 m
\end{aligned}
$$

In this case and considering this method, we could estimate the average level of coherence between these pairs in direct relationship with the difference of Baselines, which separate the orbits.
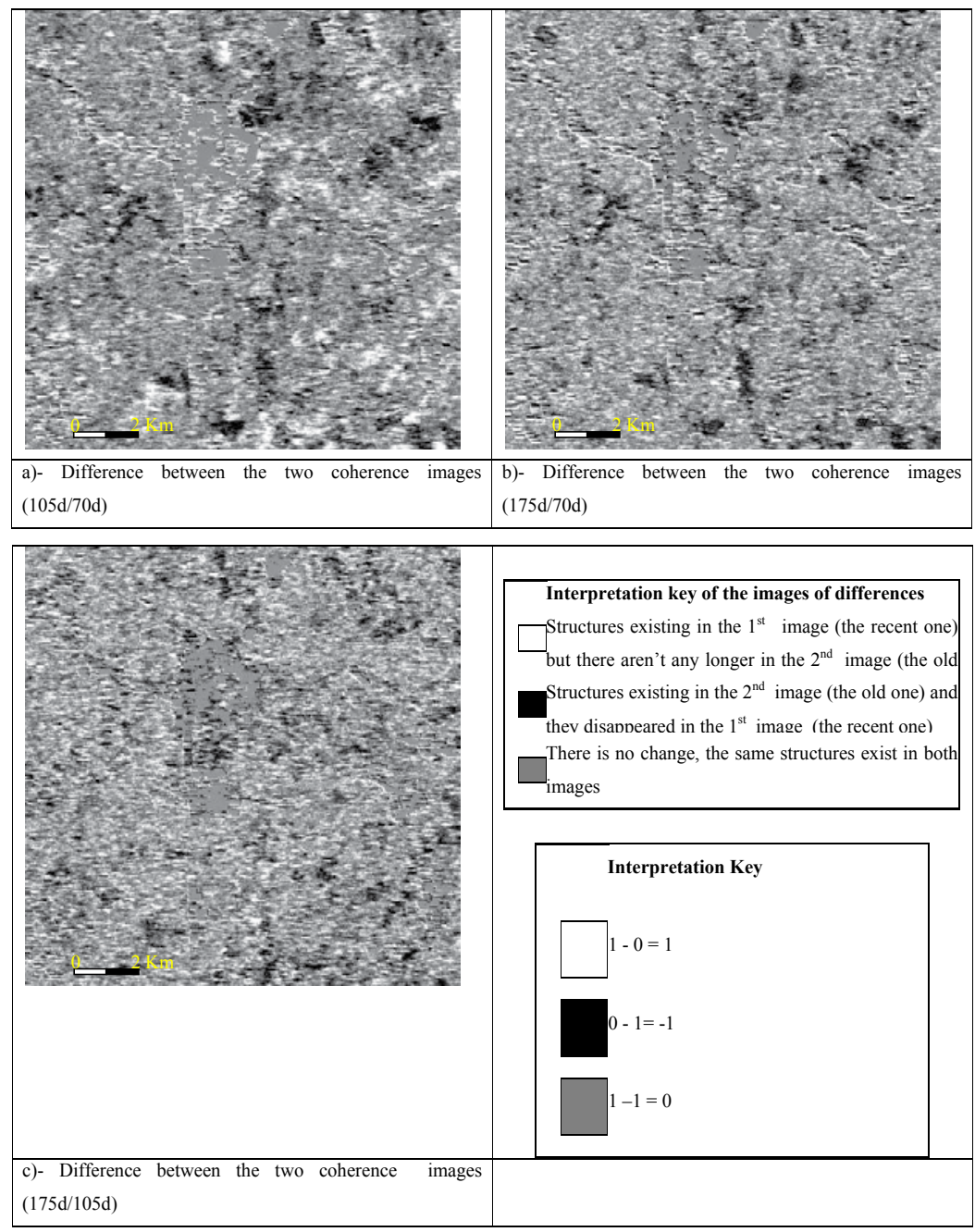

Figure 4: Differences between the two coherence images at different intervals. 
Citation: Hachemi K, Visan M, Ozer A, Grecu F, Anouche K, et al. (2013) The Interest of Coherence from Radar SAR Images in the Follow-Up of Urban Extensions of Focşani City (Romania). Geoinfor Geostat: An Overview 1:4.

\section{The coherence of the tandem pairs ERS-1/2}

This pair represents the only one that gives a good coherence of whole the scene. This coherence shows the riability of the resulting interferogram considering these two data. This pair has been used for carrying out a DEM [19]. We consider that there is no temporal decorrelation given that the time interval between the takings of the both images is at 1 day (the 28th and the 29th of May 1995). Between the acquisition dates of these radar images, there was not observed geological incident involving superior movements than 28 $\mathrm{mm}(1 / 2$ of wavelength of the band " $\mathrm{C}$ "). In the plain area, we find a good coherence, but regarding to the relief area, especially where there is vegetation, we see clearly poor coherence. Using this image of coherence, we can delimit the areas where the vegetation can be in large movement due to the wind. So the coherence image allows delimitating the two natural objects in this region, the lakes and the areas covered by vegetation. The lakes are well known and defined, particularly when they are full during the rainy seasons. They are well represented by very dark colours at coherence level at zero. This pair allowed us to calculate with high accuracy the size of the lakes and of the area covered by vegetation in the region of Buzau [20]. These results are thus explained: (i) The lakes are covered by a water surface moving continuously (wind effect on the surface), which explains the poor coherence between the images;

(ii) The relief areas appear in black; they are covered by high vegetation (forests) that can present different aspects from one image to another (e. g. window effects) which also explains the poor coherence between the images;

(iii) Finaly the plain area is probably less covered by vegetation (bare, dry soils) at the time of the image acquisitions; so there are small changes which explain the strong coherence between the images;

(iv) The urban areas due to their stability are represented by a good and strong coherence.

\section{Comparing coherence at different dates over Focşani city}

We use the coherence images with the purpose of followingup the urban areas. We have focussed on the zones in the images corresponding to the city of Focşani. Figures 2-b, c, d, and e show effectively a very good coherence for the urban area that appears in white in grey scale visualization; this corresponds to a maximum value of coherence, i.e. 1. The analysis of the coherence images at different periods allows us to find the stability (without considerable urban
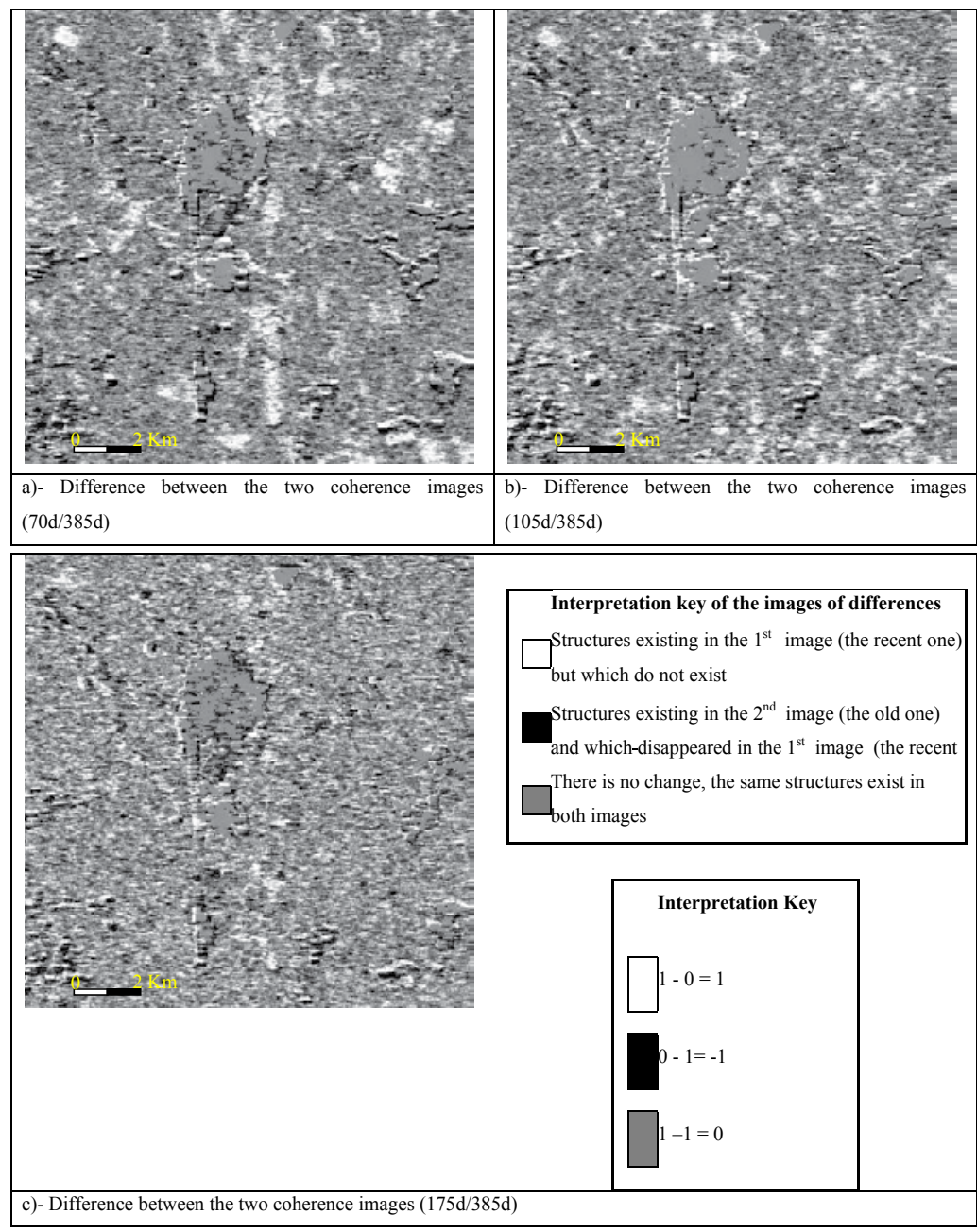

Figure 5: Difference between the two coherence images at different intervals. 
Citation: Hachemi K, Visan M, Ozer A, Grecu F, Anouche K, et al. (2013) The Interest of Coherence from Radar SAR Images in the Follow-Up of Urban Extensions of Focşani City (Romania). Geoinfor Geostat: An Overview 1:4.

extension (urban sprawl)) in almost 10 years (1995/2005) of the city of Focşani. We notice also that the three pairs, which are built with the acquired image on the 31th of January 2005, have a poor coherence (Figures 3-d, e, f), which allowed us to say that the rainfalls can be the cause of the incoherence. The comparison between the images of coherence (1995/1999 and 2004/2005) of the city of Focşani have been realized using two methods: the first one by using the difference between these images, the second one using a coloured composition of the images.

Comparing coherence differences at different dates: We performed substraction between the different periods $\left(1^{\text {st }}\right.$ image recent- $2^{\text {nd }}$ image old). This difference is shown in gray scale level. The white coulour corresponds to the recent structures of good coherence (highest level). Instead, the black colour corresponds to the poor coherence (lowest level), that is to say structures missing. This method of differences between coherence images demonstrates and confirms the good geocoding, the registration and the calibration of the coherence images between them. It shows also the structure of the ancient city of Focşani. First, we run three substractions between different images of coherence (70 days, 105 days and 175 days) in order to control the registration (calage) and to find the difference (Figure 4). Then, we processed the substractions with the oldest image of coherence with the interval of 385 days (Figures 5).

Figure 5 shows the differences between the oldest image of coherence of 1995/1996 (385 days) and the three previous recent images of coherence with time intervals of 70 days, 105 days and
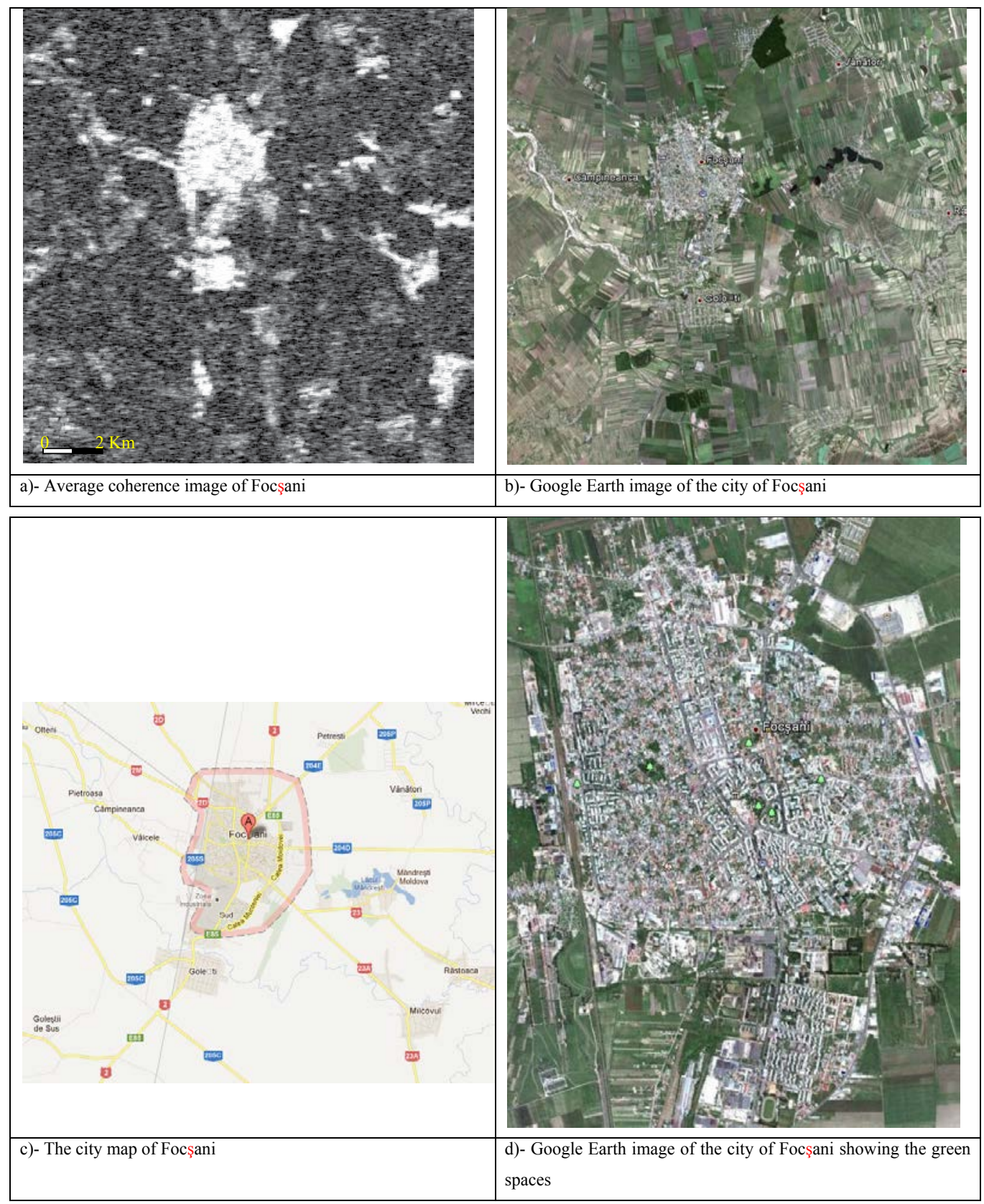

Figure 6: Comparison between the average image (12 images of coherences) and optical image of the city of Focşani. 
Citation: Hachemi K, Visan M, Ozer A, Grecu F, Anouche K, et al. (2013) The Interest of Coherence from Radar SAR Images in the Follow-Up of Urban Extensions of Focşani City (Romania). Geoinfor Geostat: An Overview 1:4.

175 days (2004/2005). The structures of the city unchanged are represented and delinated in gray colour. Instead, the white areas represent the most recent structures, which didn't exist in the years of $1995 / 1996$. The black colour in the image represents the structures or the buildings that existed in 1995/1996 and disappeared in 2004/2005. In the center of the city of Focşani, we notice several places in black colour, which correspond to green spaces and new roads (expanded roadways). These areas replaced the buildings that previously gave a good coherence (Figure 5-a).

Figure 6 shows a comparison between the average image of the 12 calculated images of coherence (a), an optical image (b), the map of the city of Focşani (c), and a zoom of (b) over the city of Focşani showing areas with green places (d). The image of average coherence shows the stability of the city of Focşani (Figure 6-a). It is well presented and delineated in white colour, which reflects the highest rate of coherence. This comparison highlights the similarity between the areas with green places situated in the center of the city and represented by small green trees in the image (d) and those shown in the image of coherence in black colour at pixel scale (a). Figures 6-b and 6-c illustrate and confirm the delimitation of the city of Focsani compared to the average coherence image (Figure 6-a).

Comparisons using coloured compositions: We produced three images of coloured composition of the coherence of the Focşani city at different time intervals with a resolution of $20 \mathrm{~m}$. We have first made two coloured compositions by assigning the red colour to the oldest image (the pair of 05/29/1995-06/17/1996, interval of 385 days) and the green and the blue to the most recent images (the pair of
10/18/2004-12/27/2004, interval of 70 days, and the pair 12/27/200404/11/2005 of interval of 105 days). Thus, we obtain the colour at each pixel of the resulting image by the following combination (Figure 7):

$$
\mathrm{c}_{(\mathrm{p})}=\mathrm{a}_{(\mathrm{p})}[\mathrm{R}]+\mathrm{b}_{(\mathrm{p})}[\mathrm{G}+\mathrm{B}] .
$$

where $a_{(p)}$ and $b_{(p)}$ represent the values depending on the stability of elements in the pixel for the oldest and the most recent component, respectively. Thus, for one pixel appearing in black in the image 1 (the level of coherence equal to 0 ) and in white in the image 2 (the level of coherence equal to 1 ), we have:

$a_{(p)}=0$ et $b_{(p)}=1$ from where $c_{(p)}=[G+B]$, then the pixel appears "blue sky".

Thereafter, we performed a third coloured composition by assigning the red to the oldest image (the pair of $05 / 29 / 1995$ $06 / 17 / 1996$, interval of 385 days), the green to pair 10/18/2004$12 / 27 / 2004$, interval of 70 days and the blue to the most recent image (pair of 12/27/2004- 04/11/2005, interval of 105 days). Thus, we obtained the colour at the each pixel of the resulting image from the following combination (Figure 8):

$$
\mathrm{k}_{(\mathrm{p})}=\mathrm{a}_{(\mathrm{p})}[\mathrm{R}]+\mathrm{b}_{(\mathrm{p})}[\mathrm{G}]+\mathrm{c}_{(\mathrm{p})}[\mathrm{B}] .
$$

where $a_{(p)}, b_{(p)}$ et $c_{(p)}$ represent the values depending on the signal intensity of the pixel for the oldest, the intermediate and the most recent components, respectively. Thus, for one pixel appearing in white in the image 1 (the signal intensity equal to 1 ) and in black in the images 2 and 3 (the signal intensity equal to 0 ), we have:

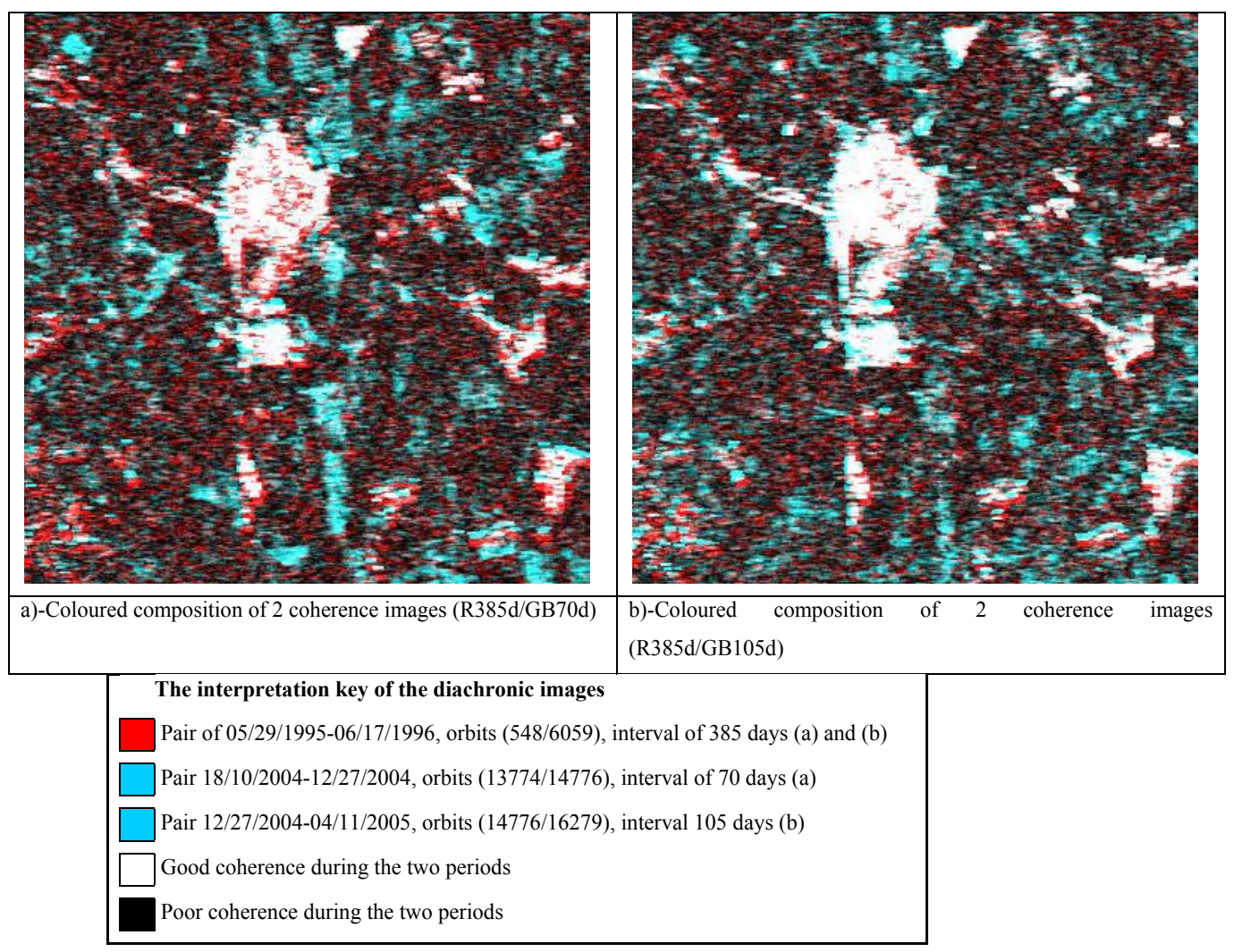

Figure 7: Coloured composition of 2 coherence images. 


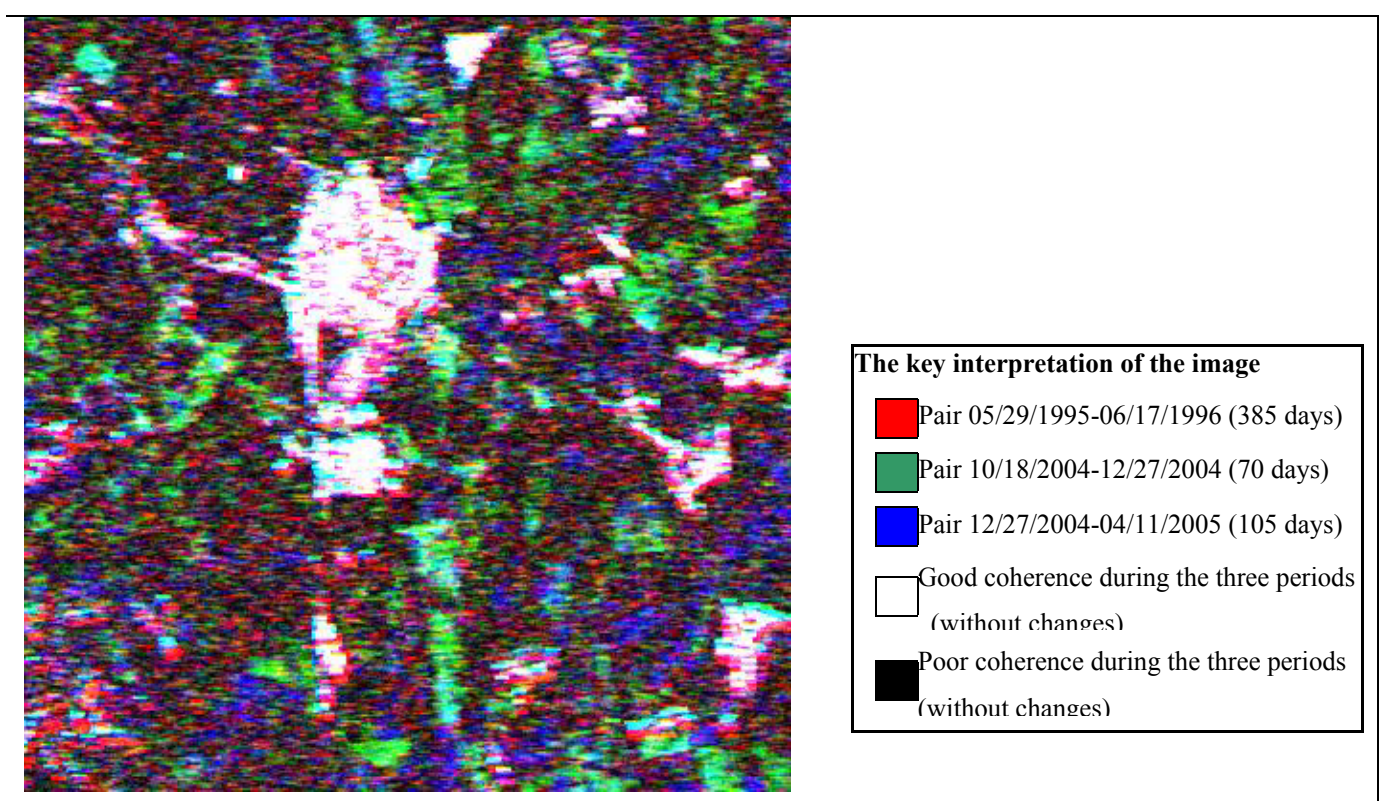

Figure 8: Coloured composition of 3 coherence images (R385d/G70d/B105d). in red.

$\mathrm{a}_{(\mathrm{p})}=1, \mathrm{~b}_{(\mathrm{p})}=0$ et $\mathrm{c}_{(\mathrm{p})}=0$ from where $\mathrm{k}_{(\mathrm{p})}=[\mathrm{R}]$, then the pixel appears

Figure 8 shows the changes between the three coherence images at different time intervals over the city of Focssani. The white colour shows the structures of the city, which didn't change all over the observed time period, i. e. over a maximum time period of 9 years. Instead, the other colours show the structures which diseappeared or appeared during these periods. The green and blue colours show the structures that appeared at the end of 2004 and the beginning of 2005. Instead, the red colour shows the structures that existed in 1995/1996 and disappeared in 2004/2005. This image demonstrates that there are some structures or constructions, which were in the center of the city and disappeared. Instead, the constructions have been multiplied outside of the city and the outskirts of the city (Figure 8). This study shows the works and the constructions built in the city of Focşani. The center of the city presents pixels in red colour, which represents the constructions or buildings, which were replaced by green spaces.

In this work, the two methods of comparison gave the same results. There are no considerable changes during the period of ten (10) years, but we should note that there are several constructions that have been proliferated to the outskirts and outside of the city. The most interesting result is related to the changes that occurred within the city. We found the renovations at the pixel scale $(20 \mathrm{~m})$. The buildings and the constructions have been replaced by green spaces that the city needed.

\section{Conclusion}

We have used the images of coherence over different time intervals with the purpose of studying and following-up the extension of the city of Focşani (Romania). Generally, cities and urban areas maintain a good coherence level due to the stability of the pixel between the SAR acquisitions. The results demonstrate effectively a very good coherence for the urban area which appears in white in gray scale visualization; this corresponds to a maximum value of coherence. The analysis of the images of coherence at different time intervals, allowed us to find the stability of the city of Focşani (without considerable extension) during almost 10 years (1995/2005). Therefore, we distinguished several constructions that have been multiplied to the outskirts and outside of the city. During the same period, we should note also that in the center of the city, there were urban renovations replaced by green spaces. We also noticed that the three pair built with the acquired image from 31/01/2005 present a poor coherence, which allows saying that the rainfalls can be the cause of the incoherence. It demonstrates that the observed incoherence is due to changes of the surface conditions between these periods. We also observed that the incoherence is most important in the pairs formed by ERS- 1 and ERS-2 than in the pairs formed by ERS- 2 and ERS-2, although the interval of time that separates them is $24 \mathrm{~h}$ (temporal decorrelation is null or identical). The coherence in the plains of Buzau is better than in the Subcarpathians and Carpathians reliefs. This study allowed us to state that the rainfalls clearly disturb the phase as in the case of the image from 31/01/2005. This study confirms the interest of the images of coherence in order to identify the spatial decorrelations of a pair of images processed by the interferometry technique (InSAR). This work also shows the importance in exploiting the coherence levels ranging between 0 and 1 in order to differenciate the decorrelations between the stable urban areas and unstable ones. Their role (coherence images) also intervenes in delineating the urban areas and the green spaces or areas covered by water. These can be also used successfully to distinguish the flooded areas from the ones unflooded. The coherence rate is higher within urban spaces than within green ones. It is almost null in the spaces covered by water (lakes, seas) and can be used in the land use. We also demonstrated that the spatial decorrelation is very poor against the time decorrelation in this case. It is of the order of one of hundredth of the maximum coherence. This incoherence is visible between the pairs of (ERS-1/ERS-2) of the interval 386 and 1646 days and (ERS-2/ERS-2) of interval 385 and 1645 days, despite the difference of $24 \mathrm{~h}$ between these four pairs (385/386 and 1645/1646). 
Citation: Hachemi K, Visan M, Ozer A, Grecu F, Anouche K, et al. (2013) The Interest of Coherence from Radar SAR Images in the Follow-Up of Urban Extensions of Focşani City (Romania). Geoinfor Geostat: An Overview 1:4.

\section{Acknowledgement}

We thank AUF (Agence Universitaire de la Francophonie) for funding the research project shared on the contribution of the multiresolution satellite imagery to monitor the natural hazards in Romania allowing acquiring the images used in this work. These images were obtained from ESA by the Laboratory of Professor André OZER (University of Liège) within the research program shared between the universities of Liège (Belgium), Paris-XII (France) and Bucharest (Romania) We also thank the Professor Gheorghe VISAN (University of Bucharest) and Mr. Dumitru BALTA from RNMA (Romanian National Meteorology Agency) for the climate data at each period of SAR images acquisition used.

\section{References}

1. Askne JIH, Dammert PBG, Fransson J, Israelsson H, Ulander LMH (1995) Retrieval of forest parameters using intensity and repeat pass interferometric SAR information. Symposium international Extraction des paramètres biogéophysiques à partir des données RSO pour les applications terrestre, Toulouse, France, 119-129.

2. Askne JIH, Dammert PBG, Ulander LMH, Smith G (1997) C-band repea pass interferometric SAR observations of the Forest. IEEE T Geosci Remote 35: 25-35.

3. Luckman A, Baker J, Wegmüller U (2000) Repeat-Pass Interferometric Coherence Measurements of Disturbed Tropical Forest from JERS and ERS Satellites. Remote Sens Environ 73: 350-360.

4. Nico G, Pappalepore M, Pasquariello G, Refice A, Samarelli S (2000) Comparison of SAR amplitude vs. coherence flood detection methods - a GIS application. Int J Remote Sens 21: 1619-1631.

5. Fransson JE S, Smith G, Askne JIH, Olsson H (2001) Stem volume estimation in boreal forests using ERS-1/2 coherence and SPOT XS optical data. Int $J$ Remote Sens 22: 2777-2791.

6. Hall-Atkinson C, Smith LC (2001) Delineation of delta ecozones using interferometric SAR phase coherence Mackenzie River Delta, N.W.T. Canada. Remote Sens Environ 78: 229-238.

7. Stabel E, Fischer $P$ (2001) Satellite radar interferometric products for the urban application domain. Adv Environ Res 5: 425-433.

8. Gray AL, Short N, Bindschadler R, Joughin I, Padman L, Vornberger P, Khananian A (2002) RADARSAT Interferometry for Antarctic Grounding-Zone Mapping. Ann Glaciol 34: 269-276.

9. Wagnera W, Luckmanb A, Vietmeiera J, Tanseyb K, Balzterc $\mathrm{H}$, et al.
(2003) Large-scale mapping of boreal forest in SIBERIA using ERS tandem coherence and JERS backscatter data. Remote Sens Environ 85: 125-144.

10. Blaes X, Defourny P (2003) Retrieving crop parameters based on tandem ERS 1/2 interferometric coherence images. Remote Sens Environ 88: $374-$ 385.

11. Hoffmann J (2007) Mapping damage during the Bam (Iran) earthquake using interferometric coherence. Int J Remote Sens 28: 1199-1216.

12. Drezet PML, Quegan S (2007) Satellite-based radar mapping of British forest age and Net Ecosystem Exchange using ERS tandem coherence. Forest Ecol Manag 238: 65-80.

13. Tanase MA, Santoro M, Wegmüller U, De La Riva J, Pérez-Cabello F (2010) Properties of X-, C- and L-band repeat-pass interferometric SAR coherence in Mediterranean pine forests affected by fires. Remote Sens Environ 114: 2182-2194

14. Bodart C, Ozer A, Derauw D (2010) Suivi de l'activité des dunes au Niger au moyen de la cohérence interférométrique ERS1/2. Bulletin de la Société Géographique de Liège (BSGLg) 54: 123-136.

15. Touzi R, Lopes A, Bruniquel J, Vachon PW (1999) Coherence Estimation for SAR Imagery. IEEE T Geosci Remote 37: 135-149.

16. Adragna F, Et Nicolas JM (2001) Traitement des images de Radar à Synthèse d'Ouverture (RSO), sous la direction de Henri Maître. Hermes Science Europe Publication, Paris, 328.

17. Vachon PW, Geudtner D, Gray AL, Touzi R (1995) ERS-1 Synthetic Aperture Radar Repeat-Pass Interferometry Studies : Implications for RADARSAT. Can J Rem Sens 21: 441-454.

18. Vachon PW, Gray AL, Mattar KE (1998) RADARSAT and ERS Repeat-Pass SAR Interferometry at CCRS. SAR Workshop '97, Tsukuba, Earth Science and Technology Organization of Japan and NASDA.

19. Hachemi K (2009) Apport de l'interférométrie radar SAR pour la réalisation d'un MNA (Modèle Numérique d'Altitude) sur la région subcarpatique de Buzău (Roumanie). Journal Analele Universitatii Bucuresti, Année LVIII : 5-38.

20. Hachemi K, Abdellaoui A, Ozer A, Grecu F, Visan M (2010) Utilité de l'image de cohérence du couple tandem dans la délimitation et le calcul des dimensions surfaciques des lacs et de la végétation dans la zone de Buzau en Roumanie. XIlème Journées Scientifiques du Réseau Télédétection de l'AUF - Monastir, Tunisie.

\section{Author Affiliation}

${ }^{1}$ Laboratoire de Géographie Physique (LGP), Université Paris-Est.Université Paris 1 -Panthéon- Sorbonne, France

${ }^{2}$ Faculty of Geography, University of Bucharest, Geomorphology-PedologyGeomatics Department, Bucharest, Romania

${ }^{3}$ Géomorphologie et Télédétection, Département de Géographie, Université de Liège, Belgium

${ }^{4}$ Department of Architecture, Science and Technology Oran University (USTO), Bir El-Djir, Algeria

${ }^{5}$ Institute of Geography, Geomorphology \& Natural Hazards Department, Bucharest, Romania

${ }^{6}$ Faculty of Electronics and Computer Science, University of Science and Technology Houari Boumediene), Bab Ezzouar Algiers, Algeria

Submit your next manuscript and get advantages of SciTechnol submissions

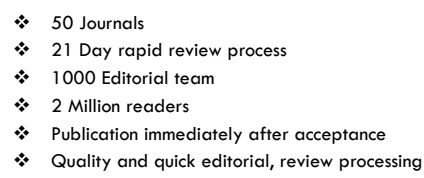

Submit your next manuscript at • www.scitechnol.com/submission 